Conceptualizing and Studying Characteristics, Units, and Fits of Persons and Environments: A Coherent Synthesis

\author{
Christian Kandler ${ }^{1}$ \& John F. Rauthmann ${ }^{2}$ \\ 1 University of Bremen (Germany) \\ 2Bielefeld University (Germany)
}

This is a preprint version of a manuscript accepted for publication in the European Journal of Personality https://dx.doi.org/10.1177/08902070211048728

\begin{abstract}
Author Notes
Christian Kandler, Department of Psychology, University of Bremen, https://orcid.org/0000-0002-9175-235X

John F. Rauthmann, Department of Psychology, Bielefeld University, https://orcid.org/0000-0001-6115-3092

Correspondence concerning this article should be addressed to Christian Kandler, Department of Psychology, University of Bremen, PO: 330440, 28334 Bremen, Germany. E-mail: ckandler@uni-bremen.de. During the time of writing this paper, Christian Kandler was supported by grants from the German Research Foundation (grant numbers: 272981829, 220286500, and 458609264).
\end{abstract}

Supplementary file: https://osf.io/k4j8h/ 


\begin{abstract}
Based on a perspective on personality coherence as the extent to which personalityrelevant characteristics are differentiated and integrated within a person in his or her environment, we propose a synthesis that builds on and harmonizes existing and partly conflicting theories, methodological approaches, and empirical findings. This understanding of personality coherence needs clear definitions of person and environment characteristics. We define traits as characteristics of the person, adaptations as characteristics of the person-in-contexts, and states as characteristics of the person-in-situations. Thus, our synthesis involves concepts of environments and person-environment units. Next, we provide testable criteria to differentiate characteristics of persons from characteristics of person-environment units and to identify dispositional traits for a narrow-sense perspective on personality coherence. We raise awareness of the importance of fit between (profiles of) person and environment characteristics for an understanding of the integrated uniqueness of persons in their environments. We outline implications of this broader perspective on personality coherence for personality development, self-regulation, social integration, well-being, and psychological interventions. Lastly, we conclude that the analysis of an individual's uniqueness and personality differences requires information about how well-defined, well-differentiated, well-integrated, and well-operationalized person(ality) variables are actually expressed in, or interact and transact with, the individual environment.
\end{abstract}

Keywords: traits; adaptations; states; context; situation; person-environment fit; personality; coherence 


\section{Conceptualizing and Studying Characteristics, Units, and Fits of Persons and Environments: A Coherent Synthesis}

Personality is most commonly defined as a system of all characteristic patterns of thinking, feeling, striving, and acting that are relatively stable and useful to distinguish a person's uniqueness from others (Baumert et al., 2017). The extent to which these personality characteristics are differentiated (i.e., distinct and specified) and integrated (i.e., organized and unified) within the individual have been originally defined as personality coherence (Allport, 1937; Fournier et al., 2015, 2021). The field of personality psychology, however, has produced varied concepts of personality characteristics (e.g., traits, motives, values, or narratives) and structurally organized systems to describe personality differences and individual uniqueness (e.g., Fajkowska, 2018; McAdams, 2013; McCrae \& Costa, 2021; Mischel \& Shoda, 1995). Not surprisingly, different approaches to conceptualizing and operationalizing personality coherence have also been proposed (e.g., Fournier et al., 2015; Human et al., 2014; Reese et al., 2011). Thus, there is no sufficiently common understanding of what personality and a coherent person's uniqueness comprises. However, to avoid misunderstandings, misleading disputes, and unnecessary jingle-jangle fallacies ${ }^{1}$ (Pedhazur \& Schmelkin, 1991), clearly defined, ideally formalized, and empirically testable conceptualizations are needed.

Although several conceptualizations have explicitly emphasized the active role of persons in their environments for their own personality stability and change (e.g., Cervone \& Shoda, 1999; Deci \& Ryan, 2012; Dunlop, 2015), the complex dynamic interdependences between individual tendencies and environments have rarely been operationalized in research on the development of individual uniqueness (Fraley \& Roberts, 2005; Wagner et al., 2020). A full understanding of personality differences and the individual uniqueness, however, has to include the persons' characteristics, the characteristics of their environments, and the extent to which persons and their environments fit. Personality coherence can then be defined as the extent to which personality-relevant characteristics are differentiated and integrated within a person in his or her environment. This perspective does not only require common concepts and measures of characteristics of the person, but must also involve concepts and measures of characteristics of environments and person-environment units and fits.

\footnotetext{
${ }^{1}$ Jingle fallacy: Mistaken assumption that two different phenomena are identical because of the same label. Jangle fallacy: Mistaken assumption that two identical phenomena are different because of different labels.
} 
The major aim of this contribution is to define characteristics of persons and person-environment units for the analyses of intra-individual variability, interindividual differences, and personality coherence. Based on these definitions, we outline implications of the degree of fit between person variables and specific environment variables (i.e., variable-centered), or between a person's profile of variables and constellations of environment variables (i.e., person-centered), for personality development, identity formation, well-being, and psychological interventions. We aim to provide a coherent synthesis on three questions that need to be addressed when studying personality coherence: (1) How can characteristics of persons and person-environment units be differentiated and integrated? (2) How can persons and environments fit? (3) How can person-environment fit help to explain behavioral consistency, developmental trends, well-being, and effects in intervention programs? To this end, we do not need to reinvent the wheel, but aim to build on existing theoretical concepts, put verbal (pieces of) definitions into more formalized terms, and integrate existing methodological approaches and empirical findings. The result is an integrative and flexible approach that can afford a deeper understanding of personality coherence.

\section{Question 1: How Can Person(ality) Characteristics and Characteristics of Person(ality)-Environment Units Be Differentiated and Integrated?}

As a starting point, we define basic person(ality) and environment variables because the scientifically sufficient description of an individual's uniqueness requires clearly defined variables and units of analysis (Smaldino, 2020). We deliberately parenthesize "-ality" to take into account that we can differentiate between personality characteristics and other person characteristics depending on the definition of what constitutes a "personality" characteristic. Several concepts of human psychological characteristics have been termed personality characteristics so far, such as temperament features, cognitive abilities, motives, major life goals, value priorities, interests, or self-concepts because their measures indicate variations among individuals with considerable stability over time. However, can any observable characteristic of persons that shows a high degree of relative (i.e., rank-order) stability be considered as personality characteristic? We doubt this as we will outline in the following where we introduce the building blocks of our synthesis. 


\section{Measurement Adequacy}

Research on personality-relevant characteristics and the extent to which all of these characteristics are differentiated and integrated within the individual has to start with a definition of what personality is and an operationalization that adequately approaches this definition. Only relatively stable characteristics of a person can be termed personality characteristics against the background of most definitions of personality, such as the working definition by Baumert and 18 other colleagues (2017, p. 527): "A person's characteristic pattern of behaviours in the broad sense (including thoughts, feelings, and motivation) ... [that] is relatively stable across time and useful to distinguish this individual from others." This means that a person's manifestations (or profile) of characteristics relative to other persons' manifestations (or profiles) of the same characteristics have to remain enduring, at least for so long as is necessary to observe or detect characteristic differences between persons. One way to approach this definition could be to stipulate that personality characteristics show perfect rank-order stability over a reasonable interval of time. This can be tested empirically with adequate measures of persons' observable characteristics. Adequate measures are adjusted for both random and non-random error of measurement because instability can be attributable to the fact that each psychological measure can vary due to random (i.e., unsystematic) error of measurement (Steyer, 1989; Steyer et al., 2015), whereas stability can be attributable to stable non-random (i.e., systematic) measurement artifacts or other stable characteristics, but not necessarily attributable to the psychological characteristic of interest (Cronbach \& Meehl, 1955; Hoyt, 2000; Kandler et al., 2010).

Each measurement of a person's characteristic $Y_{i k t}$ (in the broadest sense) with an indicator $i$ (e.g., a specific item asking for typical thinking, feeling, striving, and acting) and a specific method $k$ (e.g., test, observation, self-report, etc.) at a given measurement occasion $t$ represents a characteristic more or less adequately in terms of a cross-indicator cross-method true score $\tau_{t}$ at time $t$ (with a specific weight $\left.\lambda_{i k t 1}\right)$ - irrespective of whether or not the measurement is intended to capture a stable personality characteristic (e.g., a person's typical emotionality level or momentary mood). This true score can be interpreted as a convergently valid reflection of a characteristic beyond (a) indicator-specific contributions $I_{i t}$ with the weight $\lambda_{i k t 2}$, (b) non-random method-specific artifacts $M_{k t}$ with the weight $\lambda_{i k t 3}$, and (c) random error of measurement $\varepsilon_{i k t}: Y_{i k t}=\lambda_{i k t 1} * \tau_{t}+\lambda_{i k t 2} * I_{i t}+\lambda_{i k t 3} * M_{k t}+\varepsilon_{i k t}$ 
(Campbell \& Fiske, 1959; Eid et al., 2003; see also Supplement A for more details). Repeated measurements of same subtests or items across measurement occasions may produce specific stabilities due to the method of measurement $k$ (methodspecific stability) and/or relevant aspects, facets, or nuances of a broad psychological characteristic (indicator-specific stability), such as affective, behavioral, cognitive, and motivational expressions ( $a, b, c$, and $d$; Wilt \& Revelle, 2015) that are often confounded with the specific measurement methods or items (McCrae \& Mõttus, 2019). However, only the true-score variable can account for the covariance across measurement methods and indicators of a broad characteristic defined as encompassing affective, behavioral, cognitive, and motivational components ${ }^{2}$, thus representing "true" values of the relevant characteristic (see Figure 1; see also Eid et al., 2003 for specific recommendations regarding model identification in multiindicator multi-method models).

If different measurement methods, which are assumed to measure the same characteristic, are modeled, then the true score will reflect valid content of the characteristic in terms of agreement across assessment methods (Funder, 1991). Consider, for example, Maria whose anxiety level was measured with only one method (e.g., self-report). We do not know to what extent Maria's self-report converges with other data sources (e.g., clinician ratings, physiological data). And if relevant indicators encompass valid content of, or rater perspectives on, a certain psychological characteristic (e.g., worrying and fear as indicators of anxiety), then we can differentiate between (a) true stability of this characteristic, as reflected by the cross-time correlations of the true-score variables, and (b) specific stability due to the method of measurement, rater perspectives, or relevant indicator-specific content which are often confounded (see Kraemer et al., 2003; McCrae \& Mõttus, 2019; Vazire, 2010; Vazire \& Mehl, 2008). The realization of adequate measurements of psychological characteristics helps to determine the true stability of observable characteristics. However, it does not help to determine to what extent a true score

\footnotetext{
2 The consideration of several aspects, facets, and nuances of a psychological characteristic depends on the definition of the conceptual broadness of this construct, such as extraversion (Wilt \& Revelle, 2015). We can also approximate narrower characteristics (e.g., social anxiety when meeting strangers) via multiple indicators and methods measuring those indicators. However, one could also be interested in directly measuring very specific nuances of broader constructs (Mõttus et al., 2017, 2019). The narrower the concept is, the less aspects, facets, and nuances we will have to mesh into our characteristic, inferred from indicators and their methods. As a consequence, the model presented in Figure 1 can be simplified accordingly.
} 
reflects a stable characteristic of a person, properties (or influences) of the environment in which the measurement of the characteristic takes place, or properties of both the person and his or her environment.

Figure 1. Simplified representation of a balanced measurement model to visualize true-score, method-specific, and indicator-specific stability

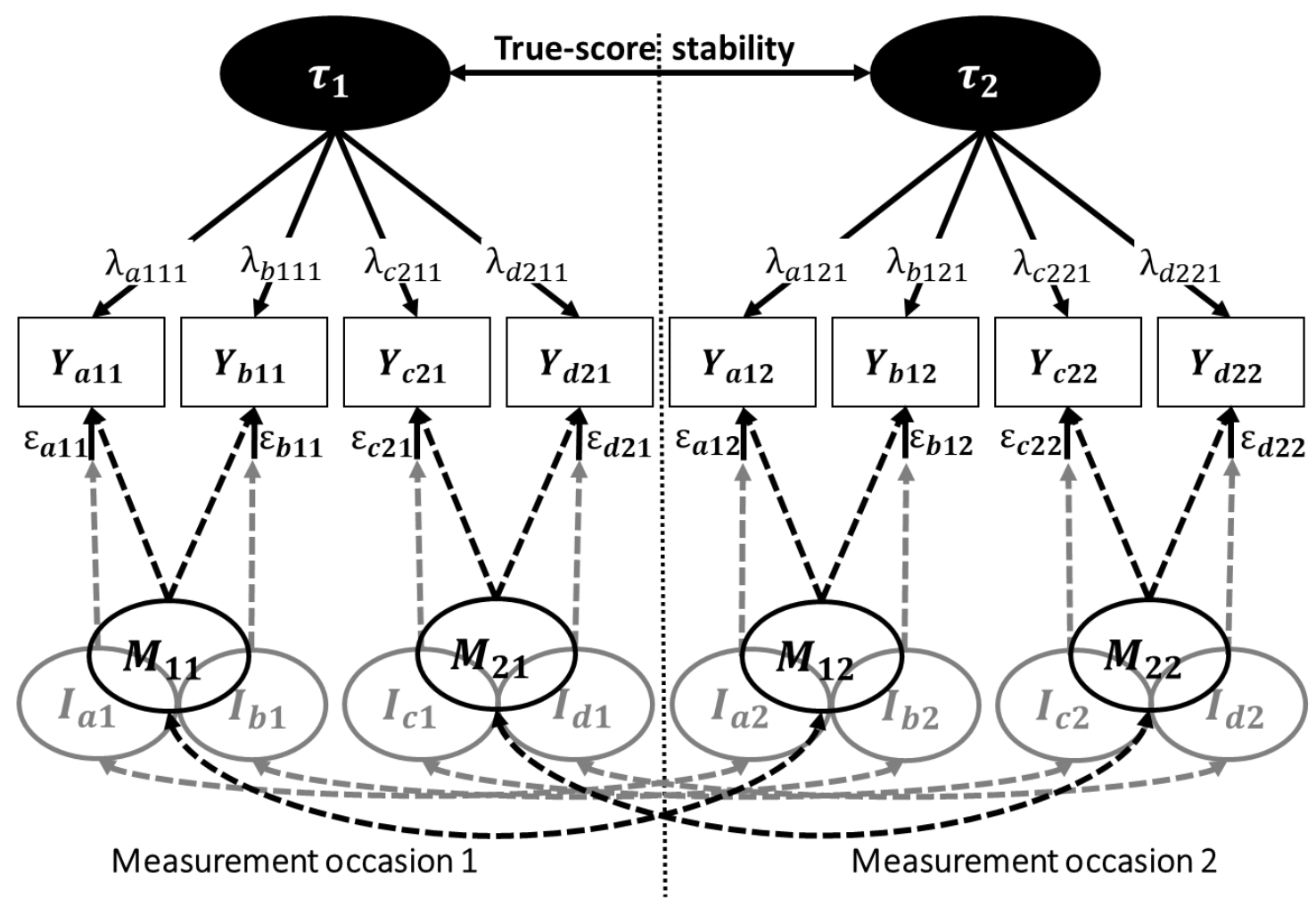

Note. $Y_{a 11}$ to $Y_{d 22}$ are the manifest variables; $\tau_{1}$ and $\tau_{2}$ are the common cross-indicator crossmethod true-score variables; $I_{i t}(i=a, b, c, d)$ are the indicator-specific variables; $M_{k t}(k=1,2)$ are the method-specific variables; and $\varepsilon_{a 11}$ to $\varepsilon_{d 22}$ are the random measurement error variables at two measurement occasions $t=1,2$. The loadings $\lambda_{i k t 2}$ and $\lambda_{i k t 3}$ are not shown. The figure illustrates characteristic-specific stability (covariance path between $\tau_{1}$ and $\tau_{2}$ ) and method-specific stability (dashed black covariance paths) as well as indicator-specific stability (dashed grey covariance paths). It also illustrates the problem of confoundedness between measurement methods and indicator-specific content $(M$ with $I)$. Specifically, if not otherwise disentangled, $M_{1}$ is confounded with $I_{a}$ and $I_{b}$, and $M_{2}$ with $I_{c}$ and $I_{d}$.

\section{Traits and States}

The true score we referred to above may reflect a stable characteristic of a person (i.e., a trait) to the extent that the stability in this characteristic across further measurement occasions is a function of the person and that the characteristic does not represent properties of the environment. If the true score is only persistent within a limited interval of time and a specific individual situation, we may have captured a characteristic of the person in this situation (i.e., including situational influences and 
person $\times$ situation interactions) that we term a state. This state, in turn, may harbor a component that accounts for relative stability over longer periods of time and consistency across different situations, which we term a trait in the common sense of a stable and consistent characteristic of a person (Epstein, 1979, 1980; Cervone \& Shoda, 1999). These concepts of traits as characteristics of persons and states as situation-dependent trait expressions integrate both a dichotomous and a continuous differentiation between traits and states (Chaplin et al., 1988; Leising et al., 2014).

Explicit mathematical definitions of traits and states based on a dynamic concept of the person and a time-dependent concept of the situation, as defined in the revised Latent State-Trait Theory (LSTT-R; Steyer et al., 2015), have several implications for their operationalization (see Supplement B for more details). First, we are generally not able to identify a psychological characteristic as either a state or trait; rather, each characteristic can be both, but to different degrees. A trait of a person cannot be captured in a situational vacuum. Thus, to derive a person's characteristic (i.e., a trait), one first needs to measure a state, which is a characteristic of the person in a situation in which the measurement takes place (Steyer et al., 1999, 2015). This state may be affected by the person, but it is also affected by the situation and the potential interaction between the (characteristics of the) person and the situation. Thus, we have to forgo the dichotomous thinking about traits and states.

Second, we are also not able to specify a psychological characteristic as either state-like or trait-like based on only one measurement occasion. Consider Maria again, whose anxiety level was measured once. We do not know to what extent Maria's anxiety level is the same (or linked with) her anxiety levels in subsequent measurement occasions. Thus, it is important to distinguish measurements of state anxiety in different occasions within the same environmental condition from trait anxiety across different environmental conditions. Regardless of whether the instruction set told Maria to report on her general anxiety (to measure a trait) or momentary levels of anxiety (to measure a state), we still need different measurement occasions (i.e., at least two) in different environmental conditions (e.g., being alone, with friends, with strangers, etc.) to disentangle a trait from state-specific deviations in a characteristic. To put it bluntly, the item "I am generally an anxious person" (phrased to measure a trait) contains both trait and state-specific components, as does the item "I am currently anxious" (phrased to measure a state). 
The extent to which trait and state-only components are captured with these items cannot be ascertained with one measurement only and is an empirical question that is best addressed with repeatedly measured (multi-indicator and multi-method) data.

Third, as a consequence of the preceding points, each true score of a measured characteristic can have a smaller or larger trait component, but the trait component is limited by the range of state variability. Traits can be seen as those more stable and cross-situationally consistent parts of states that are inherent in density distributions (e.g., Fleeson, 2001) or can act as set-points of state fluctuations (Ormel et al., 2017). A trait of a person can thus be defined as nested within the state of this person in a situation, whereby the state additionally includes situational and trait $\times$ situation interaction influences (see Supplement B for more details in formal terms). The state, in turn, can be seen as nested within the measure of a person's characteristic controlled for measurement artifacts and thus as a true score at a specific measurement occasion. This simple logic underlies several modeling approaches aiming to capture the trait and state-specific components of repeated measurements of the same characteristic from both a nomothetic interindividual approach (Steyer et al., 1999, Schermelleh-Engel et al., 2004) and an idiographic intra-individual perspective (Hamaker et al., 2007; Molenaar et al., 2009).

Fourth, the integration of the trait score within the state score allows specifying the extent to which psychological characteristics are more trait-like or state-like without assuming a crude categorical or dimensional differentiation between traits and states. Within a formalized logic, a reliable reflection of a characteristic can be termed more trait-like if the trait variance between persons is larger than the stateresidual variance: $\operatorname{Var}($ Trait $)>\operatorname{Var}($ State $)-\operatorname{Var}($ Trait $)$. Conversely, it can be termed more state-like if the reverse is true: $\operatorname{Var}($ Trait) $<\operatorname{Var}($ State)-Var(Trait). Thus, to what extent a characteristic can be termed (more of) a trait or state, respectively, is a matter of empirical tests. ${ }^{3}$

The basic test-theoretical approach outlined above can be extended in several ways by an inclusion of (a) multiple methods or raters (e.g., self-reports and

\footnotetext{
${ }^{3}$ As we already explained, such tests will have to use longitudinal data. However, it is not trivial how long the time intervals between measurements should be, and it remains an open question how large stability coefficients need to be to term a psychological characteristic as trait-like. Would correlations around .50 suffice? The answer to the latter question has consequences for longitudinal designs to differentiate a trait from its expressions in situations at certain measurement occasions. Unfortunately, no agreed-upon answers exist so far. Most researchers would simply endorse that characteristics need to be "relatively stable", without specifying the extent of stability across which time interval.
} 
informant-reports) and (b) reliable indicators of a specific characteristic (e.g., asking for the ABCDs of anxiety) to derive a better proxy of a true score (Courvoisier et al., 2008; Geiser \& Lockhart, 2012). Thus, to adequately and empirically tease apart trait and state-specific components in measures of psychological characteristics, a design is needed that incorporates multiple data sources for the characteristic, each with multiple items or tests, which are measured across different situations over a theoretically or practically relevant period of time. An instruction set, such as to rate items of the characteristics as pertaining to a person generally (trait) or momentarily in a situation (state specificity), may serve to increase or decrease trait and statespecific components, but is itself not a sufficient criterion to establish the relative traitness and stateness of the measured characteristic.

The definitions of states as characteristics of the person-in-situations and traits as characteristics of the person are helpful to overcome several vague and colloquial uses of these terms. This conceptualization of traits and states does not only allow us differentiating both, but also to integrate them into observable characteristics of persons, who cannot be observed in an environmental vacuum. In that sense, this state-trait differentiation on the one hand and trait-in-state integration on the other brings us closer to personality coherence in terms of the extent to which a person's characteristics are differentiated and integrated within the person in his or her environment. However, the state-trait differentiation and trait-in-state integration disregard a further important manifestation of psychological characteristics, the socalled adaptations, which we will discuss next.

\section{Adaptations, Contexts, Situations, and Niches}

Consider Maria again, whose anxiety level has been measured nine times over a longer period of time, with three methods at each measurement occasion (e.g., self-report, informant-report, and skin conductance responses) and each occasion reflecting different social conditions in different environmental settings (e.g., alone at home, together with a friend at a crowded party, and with colleagues at the office). Because of the multi-method assessment of Maria's anxiety, we now have a better proxy of her state anxiety level at any given measurement occasion (Funder, 1991; Kraemer et al., 2003). As there are repeated measurements, we can additionally extract a better proxy of her trait anxiety level as an aggregate across all nine occasions (Hamaker et al., 2007; Molenaar et al., 2009). We can also operationalize the method specificity of a measure due to the method of 
measurement. However, we cannot differentiate Maria's state specificity from context-dependent habitual aspects of her anxiety because different social situations (being alone, with a friend, or with colleagues) are confounded with certain contexts (home, party, and office). In other words, we cannot differentiate between her situational anxiety and her contextual anxiety. To differentiate situational from contextual (expressions of) characteristics, we first need to distinguish situations from contexts.

We define context as a specific constant or recurrent environmental setting. While the context per se is constant over longer periods of time, the individual can switch between contexts (e.g., work, leisure, family, etc.). Further, more proximal contexts of a person, such as work and family, may be embedded in more distal contexts, such as society and culture (Bronfenbrenner, 1979). Switching between more distal contexts happens less frequently, but are of course possible (e.g., when moving to a new city or country). Maria may show a higher level of anxiety in one context (e.g., in the office), but not in others (e.g., at home or at a party), and this higher anxiety level may depend on the specific, stable working context (e.g., due to persistent ambiguous or inflated expectations). This context-dependent higher level (or expression) of her anxiety is habitual and thus reflects an adaptation, which is defined as "habitual reactions that people have learned in response to their specific social, cultural, and physical environments" (Henry \& Mõttus, 2020, p. 270). Thus, as persons can switch between rather stable contexts, their habitual reactions may switch. Adaptations are persistent latent repertoires (in the broad ABCD sense), but they only appear in (or are associated with) a specific constant or recurrent context.

Coming back to Maria, it might also be the case that her high anxiety level in the office at a specific time point was primarily attributable to a new colleague who was stalking her at the day when the measurement occasion at the office took place. Her short-term higher anxiety level was not affected by the specific working context but by the stalking experience. Thus, not her contextual (or habitual) anxiety was higher, but her situational (event-related) anxiety because of the short-term environmental condition of being stalked. The stalking influence can also last across contexts (e.g., party and home) within a limited time period (e.g., day or week) as long as the stalking condition or episode continues. We define those specific temporary environmental conditions or episodes as situations. A situation encompasses short-term environmental influences on individual's thoughts, feelings, 
desires, and behaviors. Thus, situations represent the given environmental condition under which an individual characteristic can be observed. A situation can last for a short while (e.g., current climate, momentary circumstances, or transitional hassles) across measurement occasions and even across contexts. However, a situation can also be very short-term (e.g., sudden stressors, events, or fleeting moments) and thus is often confounded with random occasional influences at the time a person's characteristic is observed (see Rauthmann et al., 2020, for a more detailed perspective on situations).

As states are defined as characteristics of the person-in-situations (e.g., in the LSTT-R; see Supplement B), the situation-dependent higher level (or expression) of Maria's anxiety may reflect a state. Whereas a state is mutable with varying situations on a time scale, it can be (short-term) consistent across different fastswitching contexts (e.g., at home, on the way to work, at work, etc.). In other words, a state-like (or state-specific expression of a) characteristic can be differentiated from an adaptation-like (or adaptation-specific expression of a) characteristic based on its temporal (in-)stability and (in-)consistency across contexts: A state is rather instable but potentially consistent across contexts, whereas an adaptation is stable within contexts but inconsistent across contexts. ${ }^{4}$ Similar to the differentiation between states and traits (as outlined above), the trait component of a person's observed characteristic can be defined as a characteristic of the person that is nested within the person's adaptation to a specific context. Hence, states and adaptations reflect distinct components of the true score of an observed characteristic but can overlap to the degree that the true score includes a trait component.

Before we define and describe traits, states, and adaptations as characteristics of the person and person-environment units in more detail, we need to emphasize that a differentiation between situations and contexts is not trivial. The world of human beings is complex, and so are their environments. Specific individual contexts may come along with other contexts, get mixed, combined, or blended. For example, work colleagues sometimes also become friends or spouses. Moreover, one situation may lead to another situation and so on, resulting in a non-random sequence of episodes. For example, job loss coincides with (at least temporary) unemployment and may lead to financial problems, which in turn may increase the

\footnotetext{
${ }^{4}$ Stability is defined as temporal constancy, repeatability, or recurrence of a variable in the broadest sense (i.e., across any variations in time), whereas consistency is defined as constancy, repeatability, or recurrence across any variations of environments.
} 
potential for conflicts in families. Further, context effects might interact or even correlate with specific situations, such that individuals are typically less stressed in leisure time than at work. The individual bundle or profile of interrelated contexts linked with correlated sequences of situations can be termed a person's niche (see also Rauthmann, 2021).

\section{Conceptualizing and Operationalizing Adaptations, States, and Traits}

The aforementioned example of Maria's anxiety should illustrate that one observed characteristic can reflect a trait, a state, and an adaptation concurrently but to different degrees. To differentiate these components of a measured individual characteristic means to specify to what extent a characteristic is more or less traitlike, state-like, or adaptation-like. To do so, we need to differentiate between characteristics of persons that are consistently observable across situations and contexts (traits), short-term but potentially cross-contextually consistent characteristics of person-situation units (states), and long-term stable characteristics of person-context units (adaptations). To make these distinctions, we also need to distinguish between two types of environment: contexts and situations. We propose an approach that can be seen as an extension to the LSTT-R (Steyer et al., 2015). Specifically, a trait is not only distinguished from its situational expression (a state) but also from its contextual expression (an adaptation).

A trait is defined as a relatively stable but also developing characteristic of a person. Traits can be observed across contexts and situations. However, this does not mean that the person and his or her trait levels are static. As the person can develop over time, his or her trait levels can develop and change over time. In this definition, traits are different from states $(S=T+S R$, including a person's trait $T$ and a state-specific residual $S R)$ and adaptations $(A=T+A R$, including a person's trait $T$ and an adaptation-specific residual $A R$ ), but are integrated in both.

According to latent state-trait theories (Geiser et al., 2017; Steyer et al., 1999, 2015), a person's state $S$ (e.g., current mood, need, or wakefulness) is affected by the person's trait $T$ and the situation $s$, as well as by the potential interaction between the person's trait and the situation $(T \times S): S=T+S R=T+S+T \times S$. The interaction captures how a trait effect depends on the effect of the situation (and vice versa) in addition to their main effects. Such an interaction could, for instance, capture the (actual or subjectively perceived) situational opportunity or limitation to express a trait. For example, a non-normative situation free of societal expectations 
may allow an unfolding of individual trait differences, whereas normative pressure may change average levels of states towards socially desirable standards and reduce individual trait expressions in the situation (Allport, 1937; Fleeson, 2001; Mischel, 1968). A state fluctuates with the situation and can thus be seen as characteristic of the person-in-a-situation.

Similar to the conceptualization of states, a person's adaptation $A$ (e.g., habit, attitude, or skill) is theorized to be affected by the person's trait $T$ and the context $c$, as well as by the potential interaction between the person's trait and the context $(T \times$ c): $A=T+A R=T+c+T \times c$. An individual's adaptation can thus be seen as characteristic of the person-in-a-context (McCrae, 2009; McCrae \& Costa, 2021). The expression of a person's trait in a context depends on the opportunities and limitations of the context and the individual accommodation to the specific context (McCrae \& Sutin, 2018). With changing contextual circumstances, the adaptation may totter and change because new functional accommodations are necessary.

From the verbal definitions of states, adaptations, and traits provided above (see also formal definitions in Supplement $\mathrm{C}$ ), it follows that only traits represent person-only characteristics, whereas adaptations and states represent characteristics of person-environment units, including person $\times$ environment interactions. In a similar vein, the adaptation-specific component $(A R=c+T \times c)$ and the state-specific component $(S R=s+T \times s)$ do not represent characteristics of the environment per se, but include trait $\times$ context and trait $\times$ situation interactions.

The true score of an observed individual characteristic at a given measurement occasion contains a trait component and the state and adaptation residuals beyond random measurement error and systematic effects due to measurement method and the specificity of indicators (see Figure 2 for a Venndiagram to visualize the seven theoretical variables formally defined in Supplement C). The trait scores account for a correlation between the state and the adaptation scores and as such also for cross-contextual and cross-situational consistency. Thus, traits are not separate, completely different categories of characteristics (e.g., as opposed to abilities, values, interests, etc.); rather, they have to be "peeled out" empirically from repeatedly measured psychological characteristics (that can be abilities, values, and interests, etc.) in different contexts and situations. 
Figure 2. The differentiation and integration of measurements, true scores, traits, states, adaptations, situations, and contexts

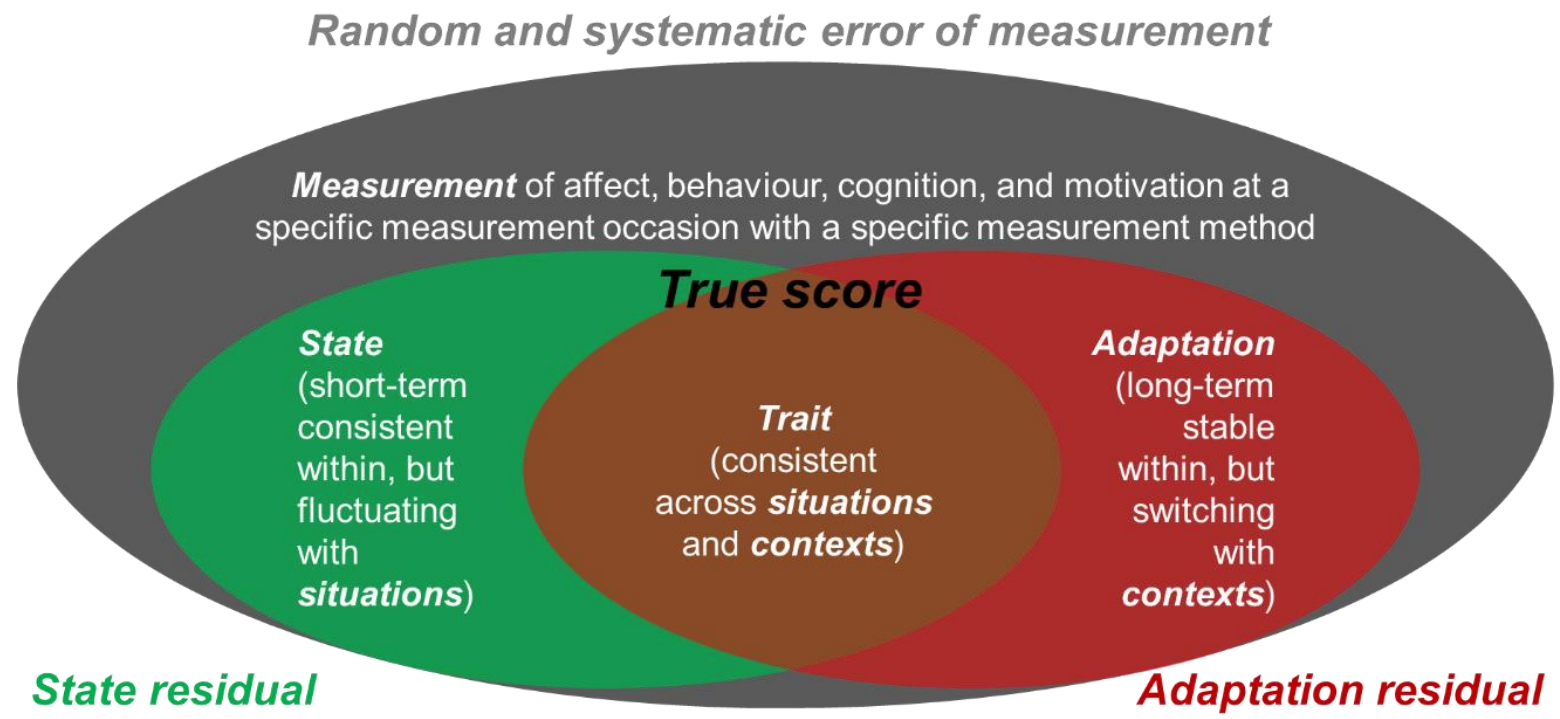

The conceptualization of traits, states, and adaptations allows their integration in several theoretical approaches, such as the Whole Trait Theory (Fleeson \& Jayawickreme, 2015), the LSTT-R (Steyer et al., 2015), and theories on the differentiation between dispositional traits and characteristic adaptations (DeYoung, 2015; McAdams \& Pals, 2006; McCrae \& Costa, 2008). It is important to note that this conceptualization is not limited to a specific single characteristic of interest. For example, a specific state (or adaptation) may emerge as a function of multiple traits in situations (or contexts): $S=T_{1}+T_{2}+\cdots+T_{n}+S R$ (or $\left.A=T_{1}+T_{2}+\cdots+T_{n}+A R\right)$. Similarly, a state (or adaptation) can be more broadly defined as a mutable (or habitual) profile of characteristics of a person in this person's individual niche. Moreover, the contributions of traits and environments could also be non-linear. However, for simplicity, we illustrate the building blocks of our approach based on repeated measures of single characteristics and linear functions (see Table 1 for an overview).

Each measurement of a person's characteristic (based on a specific indicator and method of measurement; for simplicity, we omitted relevant indices in the following) at a given point in time (i.e., the measurement occasion) within a specific situation and a specific context is the sum of the true score and error of measurement (see Figure 2 and Table 1). As a function of the person, the context, and the situation, the true score at time $t$ is completely composed of the trait as well 
as the adaptation-residual and the state-residual: $\tau_{t}=T_{t}+\left(A_{t}-T_{t}\right)+\left(S_{t}-T_{t}\right)=$ $T_{t}+A R_{t}+S R_{t}$. Thus, each observed variable $Y$ at a specific measurement occasion $t$ is the sum of the trait variable, the adaptation-residual, the state-residual, and the measurement error variable: $Y_{t}=T_{t}+A R_{t}+S R_{t}+\varepsilon_{t}$. This model equation is not identified, and the state-specific, the adaptation-specific, and residual components are confounded unless we have measured the characteristic of interest multiple times in different situations and contexts. Therefore, we need qualitative or quantitative information on individual situations and/or contexts ${ }^{5}$ to disentangle a trait score from situation-dependent and context-dependent deviations (see also Supplement $\mathrm{C}$ for more details).

Figure 3 illustrates repeatedly captured true scores in different situations and contexts. It shows that a state endures for as long as the situation endures and can be confounded with the measurement occasion (Time 1 and 7 in Figure 3). Such a confounding can occur in short-term situations as fleeting moments in intensive sampling designs (e.g., measuring variables with lags in minutes or hours) or in a longitudinal design with longer time lags (e.g., days, weeks, or even years). A similar confounding can occur for an adaptation when the characteristic is measured only once in one specific context (not shown in Figure 3).

Distinguishing contextual from situational influences on individual differences has to be taken into account within a nomothetic, variable-centered modeling strategy to examine to what extent a measured characteristic is more trait-like, adaptation-like, or state-like based on the comparison of variance components. A characteristic can be termed more trait-like if $\operatorname{Var}(T)>\operatorname{Var}(S)+\operatorname{Var}(A)-2 \times$ $\operatorname{Var}(T)=\operatorname{Var}(S R)+\operatorname{Var}(A R) ;$ more state-like if $\operatorname{Var}(S)-\operatorname{Var}(T)=\operatorname{Var}(S R)>$ $\operatorname{Var}(A)$; or more adaptation-like if $\operatorname{Var}(A)-\operatorname{Var}(T)=\operatorname{Var}(A R)>\operatorname{Var}(S)$.

The disentanglement of traits from state-specific and adaptation-specific components is not limited to a nomothetic, variable-centered modeling strategy. The cross-situational and cross-contextual trait level (i.e., an average score across contexts and situations) of a specific person's reliably measured characteristic (i.e., true score as composite across multiple measurement methods) can be disentangled from state-specific deviations due to certain situations as well as adaptation-specific

\footnotetext{
${ }^{5}$ For the measurement of situations and contexts, several structural approaches (Bronfenbrenner, 1979; Geukes et al., 2017; Rauthmann, 2015; Rauthmann et al., 2014, 2020) are useful to capture and model situational and contextual effects at a given time point.
} 
deviations due certain contexts. The complexity can be increased even further by (1) considering the links between multiple characteristics and their components and (2) analyzing how an intra-individual profile of a person's characteristics varies across contexts, situations, and time.

Table 1. Verbal definitions of basic concepts

\begin{tabular}{|c|c|}
\hline Basic concepts & Verbal definitions \\
\hline Person at Time 1 & $\begin{array}{l}\text { The person at a certain developmental stage with a certain } \\
\text { experience level at the first measurement occasion }\end{array}$ \\
\hline Person at Time $>1$ & $\begin{array}{l}\text { The same person but changed due to trait change, different } \\
\text { new experiences via former situational and contextual } \\
\text { influences and (or) person } \times \text { environment interplay }\end{array}$ \\
\hline Context & $\begin{array}{l}\text { Long-term constant or recurring, proximal and distal } \\
\text { environmental setting }\end{array}$ \\
\hline Situation & Short-term environmental condition or episode \\
\hline Measurement & $\begin{array}{l}\text { The observation of (an indicator of) a characteristic captured } \\
\text { with a certain measurement method at a specific } \\
\text { measurement occasion }\end{array}$ \\
\hline Trait & $\begin{array}{l}\text { The (cross-situationally and cross-contextually consistent) } \\
\text { characteristic of a person; the person component regarding an } \\
\text { observed characteristic }\end{array}$ \\
\hline Adaptation & $\begin{array}{l}\text { The characteristic of a person in a given context; the person- } \\
\text { in-a-context component regarding an observed characteristic }\end{array}$ \\
\hline State & $\begin{array}{l}\text { The characteristic of a person in a given situation; the person- } \\
\text { in-a-situation component regarding an observed characteristic }\end{array}$ \\
\hline Adaptation residual & $\begin{array}{l}\text { The deviation of the adaptation from the trait due to the } \\
\text { specific context and person } \times \text { context (trait } \times \text { context) } \\
\text { interactions }\end{array}$ \\
\hline State residual & $\begin{array}{l}\text { The deviation of the state from the trait due to the specific } \\
\text { situation and person } \times \text { situation (trait } \times \text { situation) interactions }\end{array}$ \\
\hline $\begin{array}{l}\text { Trait } \times \text { context } \\
\text { interaction }\end{array}$ & $\begin{array}{l}\text { Trait expression depends on the contextual opportunity to } \\
\text { express it; the contextual effect depends on the person's trait }\end{array}$ \\
\hline $\begin{array}{l}\text { Trait } \times \text { situation } \\
\text { interaction }\end{array}$ & $\begin{array}{l}\text { Trait expression depends on the situational opportunity to } \\
\text { express it; the situational effect depends on the person's trait }\end{array}$ \\
\hline True score & $\begin{array}{l}\text { Adequate reflection (good proxy) of an observed characteristic } \\
\text { at a given measurement occasion in a given environment }\end{array}$ \\
\hline $\begin{array}{l}\text { Measurement error } \\
\text { (residual) }\end{array}$ & $\begin{array}{l}\text { The deviation of the observation from the true score due to } \\
\text { random or systematic influences at a measurement occasion } \\
\text { that are not relevant to the characteristic in question }\end{array}$ \\
\hline
\end{tabular}

Note. The definitions are simplified (see Supplement C for formal definitions and details). 
Figure 3. Simplified path diagram illustrating the latent adaptation-state-trait variable decomposition approach

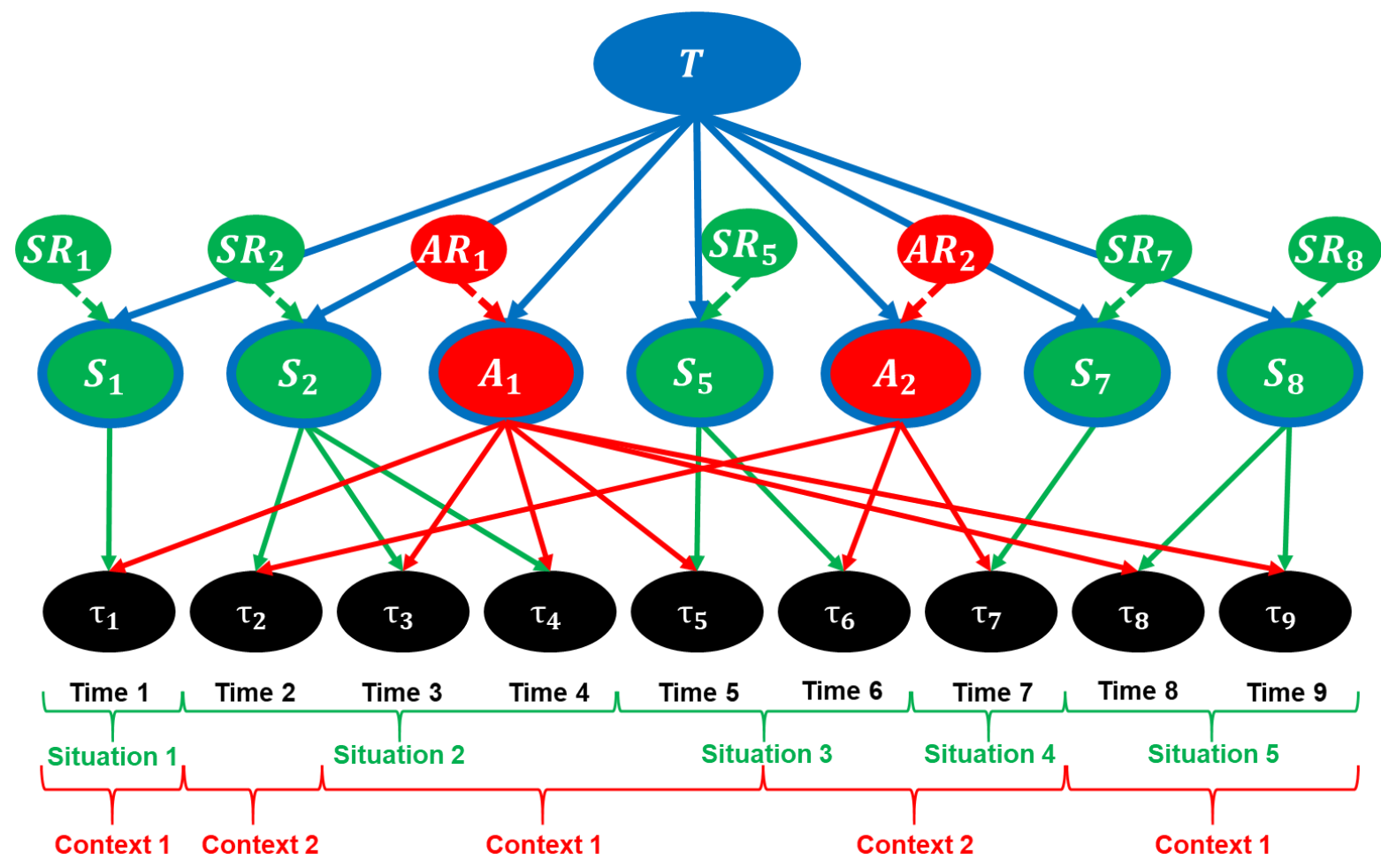

Note. $\tau_{t}$ : true scores (see Figure 1); $T$ : latent trait score; $S R_{t}$ : state residual (situational component incl. trait $\times$ situation interaction); $S_{t}$ : latent state score; $A R_{t}$ : adaptation residual (contextual component incl. trait $\times$ context interaction); $A_{t}$ : latent adaptation score. Situations (1-5) flow with the passage of time and can be shorter (e.g., Situation 1) or longer (e.g., Situation 2). Shorter situations may encompass only one relatively short state (e.g., $S_{1}$ ); longer situations can encompass a state of longer duration (e.g., $S_{2}$ ). Note that situations can overlap with a single context (e.g., Situation 1 with Context 1) or with a blend of contexts (e.g., Situation 2 blends Contexts 1 and 2). Further, contexts can appear repeatedly across time, while the same situation cannot occur again. See Supplement C for formal definitions and more details.

\section{Implications for Personality Concepts, Differences, and Coherence}

The definitions of the building blocks of our synthesis have implications for the differentiation and integration of personality-relevant characteristics in nomothetic personality models and the idiographic consideration of an individual's uniqueness. The differentiation between more trait-like, adaptation-like, and state-like characteristics allows us to specify whether or not (or rather to what degree) individual characteristics can be subsumed under the umbrella term "personality", depending on its definition. If we define personality as a system of stable characteristics that are relatively consistent across situations and contexts, then only trait-like characteristics can be termed personality characteristics. If we define personality more inclusively "as the sum of all characteristics that reflect relatively enduring patterns of emotion, cognition, motivation and behaviour in which one 
individual differs from others" (Kandler et al., 2014, p. 231; see also Baumert et al., 2017), then adaptation-like characteristics (though context-dependent) can also be subsumed under the umbrella term "personality" (Asendorpf \& Motti-Stefanidi, 2018; Henry \& Mõttus, 2020).

Based on the aforementioned definitions, state-like characteristics are not personality characteristics although they can include personality-relevant content to some degree (Danvers et al., 2020; Horstmann \& Ziegler, 2020; Rauthmann et al., 2016). However, state-like characteristics can also be personality characteristics if personality is defined as a highly dynamic and adaptive system that is not only sensitive to changing internal maturation processes and lasting changes in environmental settings but also to fluctuations in environmental conditions. As an example, Cervone and Shoda (1999, p. 30) have noted: "If personality is defined in terms of a processing system, then personality determines the if... then... relationships between the types of situations encountered (the ifs) and the person's cognitive, affective, and behavioral responses (the thens). As the ifs change, so do the thens, but the relationships between them are stable as long as the personality system remains unchanged." Under the definition of personality as a dynamic system and personality coherence as the extent to which personality-relevant characteristics are differentiated and integrated within a person in his or her environment, a full understanding of a coherent person with his or her affects, behaviors, cognitions, and desires needs to build on traits, adaptations, and states. As we have already argued, a person's actions, experiences, and development cannot be observed in an environmental vacuum. Thus, not only traits as characteristics of the person per se but also adaptations and states as characteristics of person-environment units need to be considered in the study of inter-individual personality differences, intraindividual variability, and personality coherence.

\section{Identifying Dispositional Traits}

In our conception, traits are defined as person-only characteristics or components of valid reflections of personality-relevant characteristics. They should be cross-situationally as well as cross-contextually consistent and thus relatively stable across a considerable time. A variable-centered variance decomposition approach allows the identification of a reliably measured characteristic as more traitlike (than adaptation-like or state-like). For this purpose, the timespan over which a trait-like characteristic should be relatively stable and consistent needs to be defined 
(e.g., half a year, two years, ten years, etc.). To identify a specific characteristic as a personality trait or trait-like, the latent trait component of the true-score variance in measures of this characteristic should be larger than the sum of the state-specific and adaptation-specific components: $\operatorname{Var}(T)>\operatorname{Var}(S)+\operatorname{Var}(A)-2 \times \operatorname{Var}(T)=$ $\operatorname{Var}(S)+\operatorname{Var}(A)-2 \times \operatorname{Cov}(A, S)=\operatorname{Var}(S R)+\operatorname{Var}(A R)$. This stability+consistency criterion allows the identification of whether or not (or rather to what extent) a characteristic can be considered more trait-like (vs. state-like or adaptation-like), under the condition that a design to effectively capture cross-situational and crosscontextual consistency is realized. However, this criterion cannot establish the distinctiveness and dispositional nature of potential personality traits.

Traits or trait-like characteristics are often seen as endogenous dispositions or basic tendencies. These may transact and interact with external influences that, in turn, shape the characteristics of person-environment units (i.e., the states and functional adaptations of a person in his or her environment). This fundamental statement is for the most part common to many renowned and in part conflicting theoretical models, such as the Disposition-Adaptation-Environment model (Asendorpf \& Motti-Stefanidi, 2018), the Cybernetic Big Five Theory (DeYoung, 2015), a three-layer model of personality (McAdams \& Pals, 2006; McAdams, 2015), the Five-Factor Theory of personality (McCrae \& Costa, 2008; McCrae \& Sutin, 2018), the sociogenomic model of personality (Roberts, 2018), and the LSTT-R (Steyer et al., 2015). These all share the idea that traits can account for stability and consistency in persons' behaviors and experiences. From this perspective, only traits (and not adaptations or states) can encompass the dispositional core of personality (Allport, 1931, 1966; Stern, 1935). The identification of such a dispositional core as a "person-only" fundament of personality is necessary to have promising building blocks at hand for studying the correlates and sources (e.g., genetic variants, biological markers, epigenetically anchored stressors, etc.) of persons' consistent thinking, feeling, striving, and acting across situations and contexts.

But how can we identify such a dispositional core of personality? In addition to the stability+consistency criterion, we propose six further criteria to establish a traitlike characteristic as dispositional and empirically distinct from other traits (see Table 2). Each of the seven criteria are necessary, but none of them alone is sufficient to identify a core set of dispositional traits. To be clear, any psychological characteristic (be it an ability, competency, skill, need, value, interest, etc.) can have (more or less) 
trait-like properties and, as such, be a part of the dispositional core of personality depending on the fulfillment of all seven criteria.

Table 2. Seven criteria to identify dispositional traits

\begin{tabular}{|c|c|}
\hline Criteria & Explanation \\
\hline $\begin{array}{l}\text { Stability+ } \\
\text { Consistency }\end{array}$ & $\begin{array}{l}\text { Trait components of true-score variance should be larger than } \\
\text { the sum of the state-specific and adaptation-specific } \\
\text { components: } \operatorname{Var}(T)>\operatorname{Var}(S)+\operatorname{Var}(A)-2 \times \operatorname{Var}(T) \text {, or } \\
\operatorname{Var}(T)>\operatorname{Var}(S)+\operatorname{Var}(A)-2 \times \operatorname{Cov}(A, S) \text {, or } \operatorname{Var}(T)> \\
\operatorname{Var}(S R)+\operatorname{Var}(A R) .\end{array}$ \\
\hline Universality & $\begin{array}{l}\text { Species-typical traits should be innate to all humans and thus } \\
\text { identifiable across cultures, societies, and languages. }\end{array}$ \\
\hline Heritability & $\begin{array}{l}\text { Heritability estimates }\left(h^{2}\right) \text { should be larger for traits (or trait- } \\
\text { like characteristics) than for more environmentally shaped } \\
\text { adaptation-like or state-like characteristics: } h_{\text {Trait }}^{2}>h_{\text {Adaptation }}^{2} \\
\text { and } h_{\text {Trait }}^{2}>h_{\text {State }}^{2}\end{array}$ \\
\hline Directionality & $\begin{array}{l}\text { Effects from trait-like characteristics on state-like or } \\
\text { adaptation-like characteristics should be larger than vice } \\
\text { versa: Trait } \rightarrow \text { State/Adaptation }>\text { State/Adaptation } \rightarrow \text { Trait }\end{array}$ \\
\hline $\begin{array}{l}\text { Trait-environment } \\
\text { mediation }\end{array}$ & $\begin{array}{l}\text { Transactions between traits and contexts are mediated by } \\
\text { adaptations, and transactions between traits and situations } \\
\text { are mediated by states. }\end{array}$ \\
\hline Genetic pathway & $\begin{array}{l}\text { Traits account for (or mediate) genetic (or biological) } \\
\text { differences in state-like and adaptation-like characteristics. }\end{array}$ \\
\hline $\begin{array}{l}\text { Structural } \\
\text { distinctiveness }\end{array}$ & $\begin{array}{l}\text { A limited set of divergent traits should emerge as orthogonal } \\
\text { dimensions or a distinct cluster from a set or network of } \\
\text { potential dispositional traits across diverse measures and } \\
\text { samples. }\end{array}$ \\
\hline
\end{tabular}

Dispositional traits should be species-typical and innate to all humans and identifiable across cultures, societies, and languages (universality criterion; McCrae \& Costa, 2008; McAdams, 2015). Moreover, fundaments of these dispositional traits should be observable early in life and in other species to the degree that they are evolutionarily and phylogenetically related to human beings. These fundaments may emerge as complex human traits over the life course. For example, Weiss et al. (2015) reported normative lifespan trends in measures of trait constructs to describe individual differences in apes. Those trends were largely comparable to the developmental trends in measures of the same trait constructs in humans. Moreover, Lukaszewski et al. (2020) presented research suggesting that anger could be a fundament for a descriptive dimension of agreeableness, a potentially universal trait. 
Innate fundaments of traits do not mean that these are invariant among humans, but should show substantial heritability (Kandler et al., 2014; McCrae et al., 2000).

Heritability estimates $\left(h^{2}\right)$ should be larger for trait-like characteristics than for more environmentally shaped adaptation-like or state-like characteristics (heritability criterion): $h_{\text {Trait }}^{2}>h_{\text {Adaptation }}^{2}$ and $h_{\text {Trait }}^{2}>h_{\text {State }}^{2}$. It must be noted, however, that heritability is a variance proportion - the genetic component of the overall variance in a sample at a specific measurement occasion - and thus varies as a function of sample characteristics (e.g., age, culture, and nationality) and the reliability (and validity) of measurements (Kandler, 2012; Mõttus et al., 2017, 2019). Thus, heritability estimates can vary in size across samples, but the trait heritability should be in relative terms larger than the adaptation and state heritability in any given sample. Using a variance decomposition approach to disentangle trait from statespecific and adaptation-specific components based on genetically informative data to estimate the heritability of these true-score variance components, the genetic variance $\left(\operatorname{Var}_{G}\right)$ in the trait component should be larger than the sum of the statespecific and adaptation-specific genetic components: $\operatorname{Var}_{G}(T)>\operatorname{Var}_{G}(S)+\operatorname{Var}_{G}(A)-$ $2 \times \operatorname{Var}_{G}(T)=\operatorname{Var}_{G}(S R)+\operatorname{Var}_{G}(A R)$. For example, Kandler et al. (2010) estimated 13-year stable trait and occasion-specific genetic and environmental variance components of measures based on self- and informant-reports of twins' personality characteristics. They found that the stable trait component accounted for more than $50 \%$ of the true-score variance (common variance of self- and informant-reports) at each measurement occasion in most measures. This trait variance was entirely genetic for young-adult twins and primarily genetic for mid-adult twins (> 70\%), whereas the occasion-specific components were primarily environmental. However, Kandler and colleagues were not able to disentangle occasion-specific from statespecific components, and trait- from adaptation-specific components.

As a further criterion, dispositional traits influence persons' characteristic expressions in specific situations (i.e., states) and contexts (i.e., adaptations) rather than vice versa (directionality criterion; Asendorpf \& Motti-Stefanidi, 2018; Steyer et al., 2015). For this criterion, a timespan in which a potential trait-like characteristic can be expected to be stable over time must be defined because traits can change, and environments are allowed to affect trait change via state- and adaptation-specific aspects (see Figure 4 and Supplement C). Thus, traits are not immutable but should be less amenable to external influences as opposed to state-like characteristics, 
which depend on situations, and adaptation-like characteristics, which depend on contexts. Mutual effects between traits and states or adaptations are not impossible, but effects from states or adaptations on trait change are less frequent or weaker than the reverse effects. In a recent study, Fetvadjiev and $\mathrm{He}$ (2019) examined the direction of the links between self-report measures of Big Five personality domains (proposed as dispositional trait-like characteristics) and values, self-esteem, and well-being (proposed as adaptation-like characteristics). They found that individual differences in measures of the Big Five dimensions were more stable than differences in measures of value priorities (consistent with the stability criterion) and that the Big Five domains predicted values, self-esteem, and well-being more strongly than vice versa (consistent with the directionality criterion).

Figure 4. Visualization of true-score variance decompositions into trait, stateresidual, and adaptation-residual components with effects on trait change

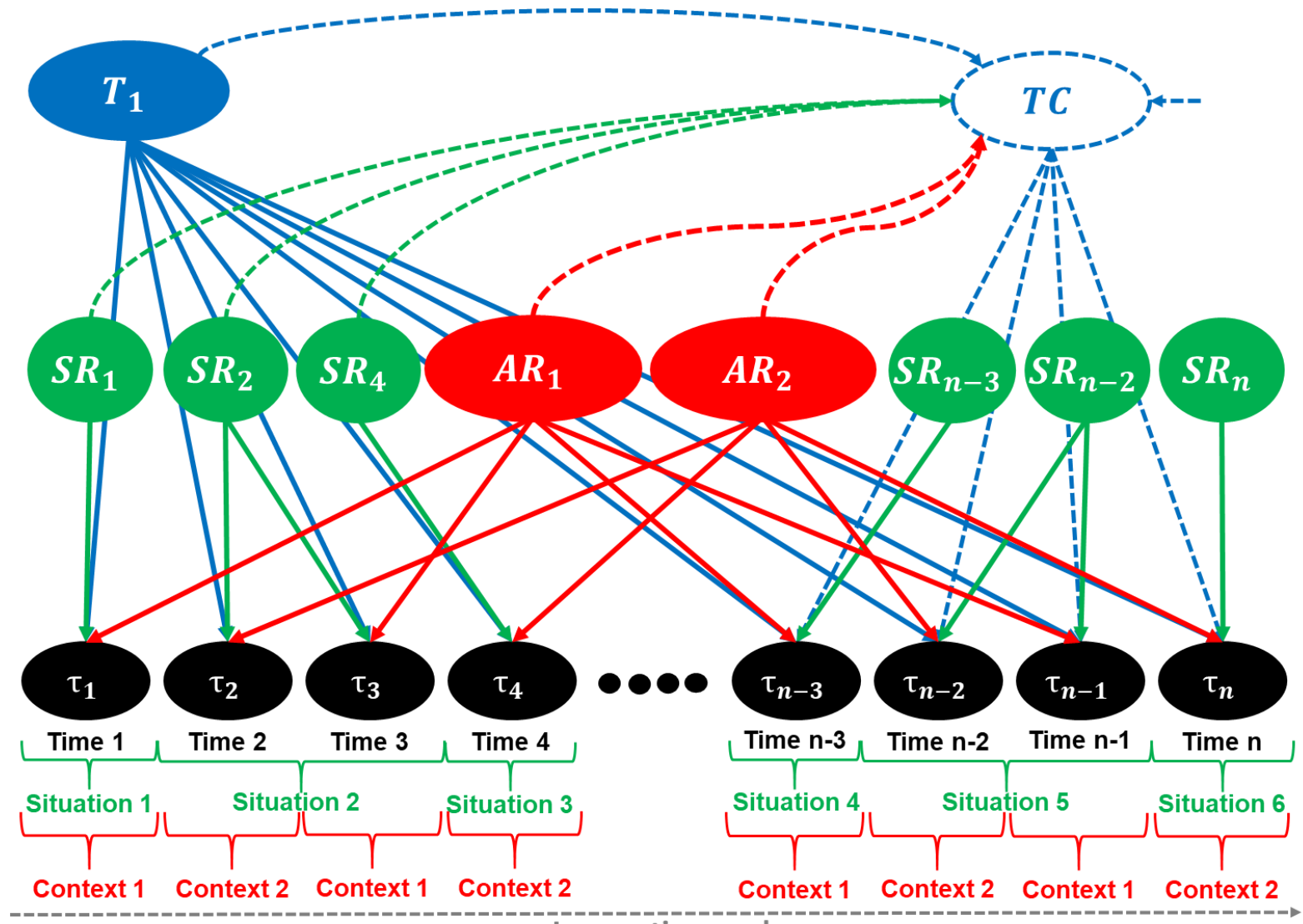

Longer time scale

Note. $\tau$ : true scores (see Figure 1); $T_{1}$ and $T C$ : initial trait score and trait change; $S R$ : state residuals (including situational and trait $\times$ situation interaction effects); $A R$ : adaptation residuals (including contextual and trait $\times$ context interaction effects). Dashed model elements reflect the trait change component (blue) and its links to state residuals (green) and adaptation residuals (red). 
The Disposition-Adaptation-Environment model (Asendorpf \& Motti-Stefanidi, 2018) proposes in line with the three-layer approach of personality (McAdams \& Pals, 2006) that adaptations should act as mediators of transactions between dispositional traits and environments. Similarly, the sociogenomic model of personality proposes states as the prime mediator between traits and environments (Roberts, 2018; Roberts \& Jackson, 2008). This is consistent with our definitions of adaptations and states, which include contextual and situational influences and can affect later traits and thus trait change (see Figure 4: state-residual $S R$ as mediator of situational influences with trait $\times$ situation interactions as well as adaptation-residual $A R$ as mediator of contextual influences with trait $\times$ context interactions on trait change). Accordingly, we propose that adaptation-like characteristics can act as mediators of contextual influences on trait change and that state-like characteristics can act as mediators of situational influences on trait change (trait-environment mediation criterion).

Similar to the role of states and adaptations as mediators of environmental influences on traits, dispositional traits should mediate (or rather account for) genetic influences on states and adaptations (DeYoung, 2015; Kandler et al., 2010). As a consequence of this genetic pathway criterion (Kandler et al., 2014), the genetic variance in state-like and adaptation-like characteristics should be accounted for by the genetic variance in trait-like characteristics. For example, Weiss et al. (2008) found that the entire genetic variance in subjective well-being could be fully explained by the genetic variance in self-rated neuroticism, extraversion, and conscientiousness as potential trait-like characteristics. Although the authors could not differentiate between trait, state-specific, and adaptation-specific components in their measures, their results suggest that well-being may not be part of the dispositional core of personality.

The aforementioned criteria cannot establish structural divergence of trait constructs across diverse measures and samples (structural distinctiveness criterion). However, distinct characteristics are necessary to parsimoniously but sufficiently reflect the wide bandwidth of the dispositional core of personality. There are several useful statistical approaches to establish a characteristic as distinct from other characteristics. For example, the multitrait-multimethod approach (Campbell \& Fiske, 1959) can be based on confirmatory factor analyses (Eid et al., 2003; Funder, 1991 ) to establish the discriminant validity of traits. In addition, network analyses can 
complement factor analyses by fostering important insights into the distinctiveness versus redundancy of traits based on low versus high clustering coefficients of network nodes without relying on latent factors (Costantini et al., 2015).

Several studies have (more or less intentionally) tested the distinction between concepts of traits, adaptations, and states against the background of some of the mentioned seven testable criteria. For example, interests have been often conceptualized as trait expressions in individual contexts (McCrae \& Costa, 2008). However, measures of interests in global domains, such as social, cultural, and intellectual activities, are as stable and heritable as measures of traits (Kandler et al., 2011; Low et al., 2005). They do not only mediate (genetic) variance in measures of temperamental and cognitive traits or other traits' effects on activities and experiences in work and life environments, but also show a substantial proportion of unexplained (genetic) variance (Kandler et al., 2011; Stoll et al., 2017; Usslepp et al., 2020). Moreover, interests show equivalent bidirectional associations with other relatively stable characteristics over time (Hoff et al., 2020; Kandler \& Piepenburg, 2020). Thus, almost all studies point to the conclusion that interests are at least as trait-like as other constructs commonly conceptualized as dispositional traits, such as the Big Five domains and intelligence. It thus stands to reason that central interest domains may capture core motivational aspects of personality (Stoll et al., 2020).

Despite these studies, systematic investigations to differentiate person characteristics formally defined as traits from adaptations and states, conceptualized as person-in-environment characteristics, based on all seven criteria still remain to be carried out. Such a research program would not only unravel trait-like, state-like, and adaptation-like characteristics, but also helps to detect and avoid mistaken assumptions (e.g., that interests are not trait-like characteristics).

\section{Implications for Person(ality) Coherence}

Identifying dispositional traits with the criteria mentioned above and specifying how these traits are differentiated and integrated within a finite set of trait constructs can provide insights into what kind of person an individual is (McCrae \& Costa, 2021). For example, trait profiles can be used to classify individuals. How consensually an individual's trait profile can be observed and judged by well-informed others (e.g., partners, friends, or relatives), operationalized as cross-informant profile correlations (or consensus), may depend on the consistency and stability of this person's traits (Human \& Biesanz, 2013). Thus, personality coherence in the sense 
of a person's consensually perceived, consistent, and stable personality trait profile can be best operationalized with the individual's trait configurations.

However, there is more to personality than dispositional traits to understand a person's uniqueness in how individuals act in environments and how they experience the world and themselves in the world. A description of the whole uniqueness of persons and an understanding of their development thus has to go beyond single trait-like characteristics or trait profiles and has to focus also on their environments (Allport, 1937). Or, as William Stern (1935) put it: "The dispositions themselves are only potential. (...) To become actual, they require integration with factors of the outer world" (p. 271). Most observable characteristics emerge as situationally mutable states or contextually malleable adaptations. Thus, on the one hand, states (i.e., person-in-situation characteristics) and adaptations (i.e., person-in-context characteristics) are important to understand personality coherence in the sense of an integrated person(ality) into the outer world (i.e., which person's traits are expressed in which situational states and which contextual adaptions). On the other hand, we also need to attend to the congruence of a person(ality) with the outer world, or in other words, to person(ality)-environment fit (P-E fit).

\section{Question 2: How can Person(ality) Characteristics and Environments Fit?}

We see P-E fit (vs. misfit) as an important concern of personality (in)coherence. Fit can be conceptualized in several ways (see, e.g., Edwards et al., 1998; Kristof-Brown \& Guay, 2011). We define fit (vs. misfit) as the optimal match (vs. mismatch) between characteristics of persons (i.e., traits) or profiles of traits and various aspects of their environment or constellations of them (i.e., niches) to produce the "best" (vs. "worst") outcome for an individual in terms of quality (e.g., selecting a fitting spouse) and quantity (e.g., reaching high marital satisfaction). For a more complete understanding of a person's feeling, thinking, striving, and acting the way he or she does in his or her environment, we need to glean insights on the person's fit to his or her environment. States and adaptations have been conceptualized as characteristics of person-environment units, of which states are temporary but can be relatively consistent across contexts, whereas adaptations are relatively stable but context-dependent. Thus, the degree of person-situation fit (i.e., when traits and situations match) and person-context fit (i.e., when traits and contexts match) has consequences for individual adaptations and states, and thus for how a person feels, thinks, strives, and acts. In the following, we describe how P-E 
interactions, correlations, and transactions (Rauthmann, 2021) are involved in processes of P-E fit(ting).

\section{Person(ality) $\times$ Environment Interactions}

As already outlined, the conceptualization of adaptations and states does not only include the additive contribution of the person's traits and contextual or situational influences, but also trait $\times$ context and trait $\times$ situation interactions. An interaction can have many faces and thus differently inform about P-E fit. For example, it encompasses the differential sensitivity of persons' dispositional traits to environments or the differential opportunity in environments to express individual traits (Blum et al., 2018; Ellis et al., 2011). Further, the same environment can provide a better fit to one person's trait or profile of traits and thus facilitate this person's personality expressions, but a worse fit to another person's trait or profile of traits and thus limit this person's expression. ${ }^{6}$ Hence, person(ality) $\times$ environment interactions can be interpreted against the background of P-E fit to the degree that (1) an individual trait or profile of traits can be optimally expressed in an environment and (2) a person's trait or profile of traits is sensitive to environments so that an optimal outcome for the person can be the result.

While trait, state-specific, and adaptation-specific components of measures of psychological characteristics can be isolated and specified as latent variables in hierarchical models (see Figure 3 and Supplement $\mathrm{C}$ ) or multilevel approaches, the specific kinds of trait $\times$ environment interactions are hard - though not impossible to isolate from the sole latent environmental contributions, in particular at the individual level. Dispositional trait components in measures of potential personality characteristics can be isolated from contextual and situational influences as well as trait $\times$ context and trait $\times$ situation interactions, provided that the persons' contexts and situations are known (i.e., measured) and the interactions specified in a model (Geiser et al., 2015; Hintz et al., 2019; Nestler et al., 2019).

\section{Person(ality)-Environment Corrrelations}

Complicating things further, persons are self-determined and not only passive recipients of environmental influences, and they can drive their own development (Wagner et al., 2020). Persons with certain levels or profiles of traits are attracted to or evoke certain environments that may show better fit to them, or they avoid

\footnotetext{
${ }^{6}$ See also Humberg et al. (2019) for an interesting overview on how and when a complex effect pattern can be interpreted as fit between $P$ and $E$ variables to produce outcomes.
} 
environments that do not fit. They are not only able to "select" potentially fitting niches, they can also modulate existing environments, and even create new ones (Shiner \& Caspi, 2003). These kinds of non-random exposure of persons (including their genetic makeup) to environments (Scarr \& McCartney, 1983) should serve to increase P-E fit, depending on people's opportunities (i.e., personal and environmental resources) to do so. Thus, they may lead to non-random associations (covariance or correlation) between persons and environments (Briley et al., 2018; Fraley \& Roberts, 2005; Kandler et al., 2021).

Non-random exposure of persons to specific environments also produces nonrandom trait-environment associations. As a consequence, individual differences in adequately measured characteristics $\operatorname{Var}(\tau)$ may not only reflect trait differences $\operatorname{Var}(T)$, environmental variance $\operatorname{Var}(E)$, and variance due to trait $\times$ environment interactions $\operatorname{Var}(T \times E)$, but also trait-environment covariance $\operatorname{Cov}(T, E): \operatorname{Var}(\tau)=$ $\operatorname{Var}(T)+\operatorname{Var}(E)+\operatorname{Var}(T \times E)+2 \times \operatorname{Cov}(T, E)$. Hence, variance in both adaptations $\operatorname{Var}(A)$ and states $\operatorname{Var}(S)$ can be decomposed into trait variance $\operatorname{Var}(T)$, environmental (contextual or situational) variance $\operatorname{Var}(E)=\operatorname{Var}(s)+\operatorname{Var}(c)$, variance due to an interaction between traits and environments $\operatorname{Var}(T \times E)=$ $\operatorname{Var}(T \times s)+\operatorname{Var}(T \times c)$, and twice the covariance between traits and environments $\operatorname{Cov}(T, E): \operatorname{Var}(A)=\operatorname{Var}(T)+\operatorname{Var}(c)+\operatorname{Var}(T \times c)+2 \times \operatorname{Cov}(T, c)$ and $\operatorname{Var}(S)=$ $\operatorname{Var}(T)+\operatorname{Var}(s)+\operatorname{Var}(T \times s)+2 \times \operatorname{Cov}(T, s)($ see Figure 5).

Figure 5. Simplified visualization of adaptation and state variance decompositions allowing for trait-environment covariance (double-headed arrow paths) and trait $\times$ environment interaction (dotted paths)

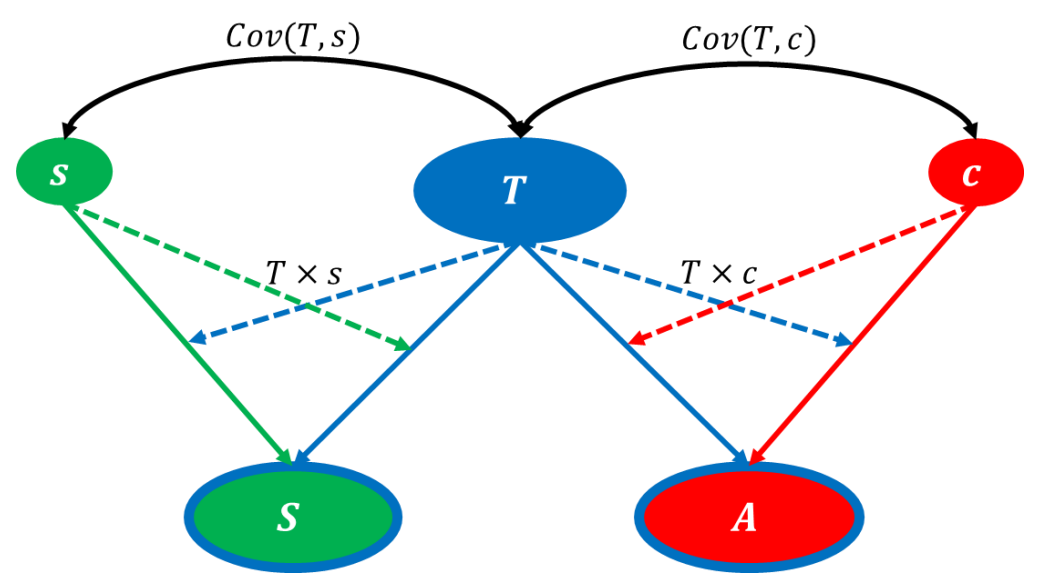

Note. $T$ : trait; $s$ : situation; $S$ : state; $c$ : context; $A$ : adaptation; $\operatorname{Cov}(T, s)$ : trait-situation covariance; $\operatorname{Cov}(T, c)$ : trait-context covariance; $T \times s$ : trait $\times$ situation interaction; $T \times c$ : trait $\times$ context interaction. 
As P-E fit is defined as the optimal match between persons' (profiles of) traits and (profiles of) characteristics of their environments that produces the best outcome for them, P-E fit does not necessarily come along with high positive trait-environment correlations, but rather with an optimal level of correlation. For example, in case of fit between spouses' personalities (where the latter can be seen as social contexts), a better fitting partner may be one with a comparable level of religiousness ("birds of a feather flock together" as supplementary fit; Muchinsky \& Monahan, 1987), whereas a submissive partner may be more attracted to a dominant partner ("opposites attract" as complementary fit). However, spousal similarity shows only small linear associations with relationship satisfaction (Watson et al., 2004; Robins et al., 2000). If robust, this could suggest that neither completely similar nor complementary partners may in general be the best choice. It may also suggest a non-linear (e.g., Ushaped) association between satisfaction and P-E fit, ranging from supplementary to complementary fit. An alternative operationalization of fit could be rather idiographic in terms of which optimal outcomes are produced for a specific person. For a personcentered approach, Rauthmann (2021) described several further options to operationalize P-E fit based on correlations at an individual level, such as the profilelevel correlations between persons' profiles of traits and corresponding niche variables or an individual index of person-environment correlations.

\section{Person(ality)-Environment Transactions and Fitting}

$\mathrm{P}-\mathrm{E}$ fit does not only appear to some degree in person(ality) $\times$ environment interactions or result from directional person(ality) $\rightarrow$ environment effects (Scarr, 1992), it can also emerge from dynamic bidirectional transactions between persons' dispositional traits and environments over time, generating or increasing the nonrandom (i.e., positive and negative) associations between persons and environments (Fraley \& Roberts, 2005). The associated process can be seen as P-E fitting. As adaptations and states are conceptualized as person-in-environment characteristics, they are the variables that both (1) can directly transact with environments and (2) act as mediators for trait-environment transactions (see trait-environment mediation criterion in Table 2). Thus, two different trait-environment transactions can be distinguished: Trait-context transactions mediated by adaptations and trait-situation transactions mediated by states. Furthermore, we can differentiate between these distal transactions and four more proximal trait-adaptation, trait-state, adaptation-context, and state-situation transactions, as illustrated in Figure 6. 
Figure 6. Simplified visualization of different forms of person $\times$ environment

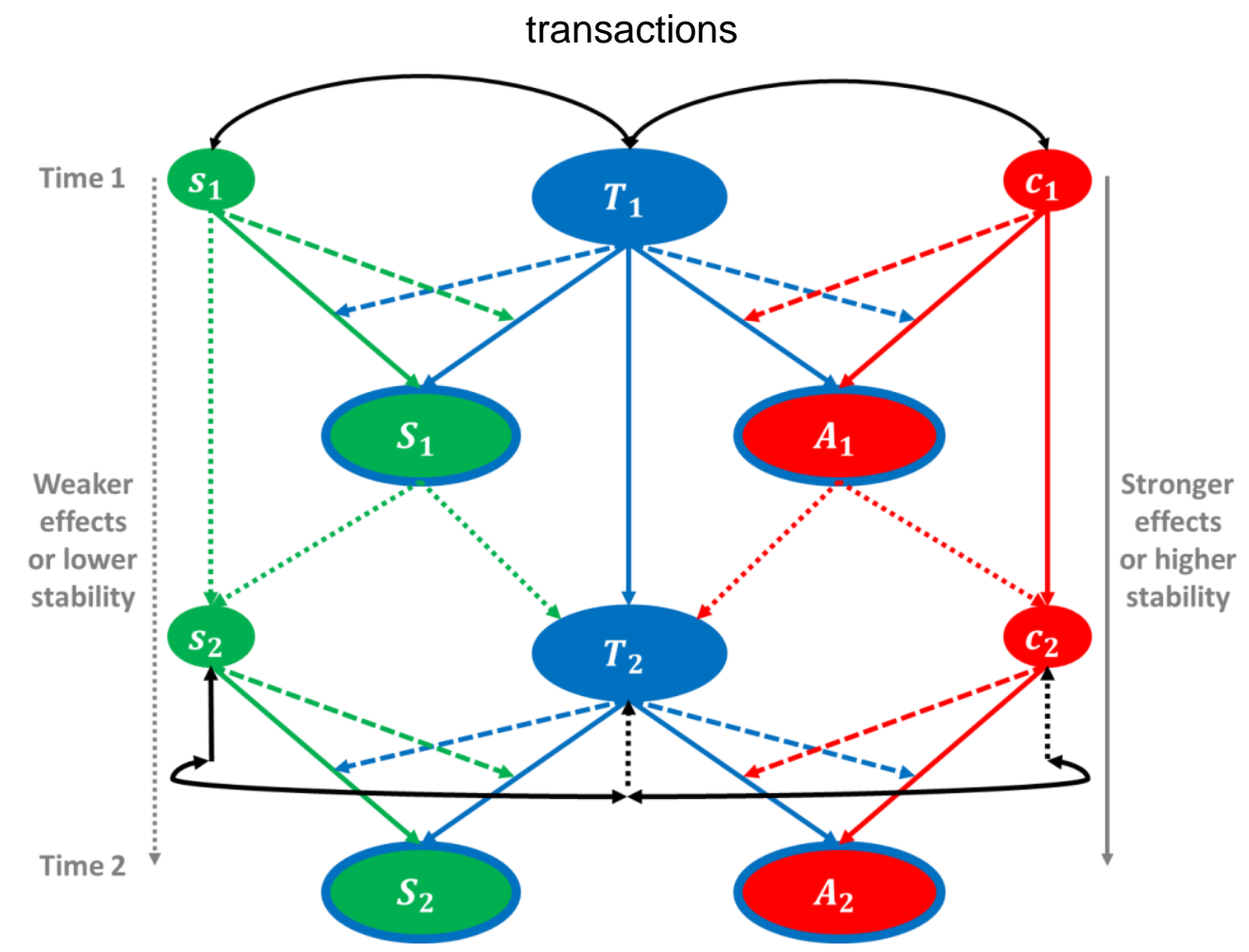

Note. $T_{1}$ and $T_{2}$ : highly stable trait scores at times 1 and 2 with $T_{1} \approx T_{2}$ or $\operatorname{Cor}\left(T_{1}, T_{2}\right) \rightarrow 1 ; s_{1}$ and $s_{2}$ : situation factors at times 1 and 2 with $s_{1} \neq s_{2}$ or $\operatorname{Cor}\left(s_{1}, s_{2}\right) \rightarrow 0 ; c_{1}$ and $c_{2}$ : highly stable context factors at times 1 and 2 with $c_{1} \approx c_{2}$ or $\operatorname{Cor}\left(c_{1}, c_{2}\right) \rightarrow 1 ; S_{1}$ and $S_{2}$ : states at times 1 and 2 , weakly linked via trait scores; $A_{1}$ and $A_{2}$ : highly stable adaptation scores due to stable trait scores and stable contextual factors. As a consequence, the (transactional) effects between traits, adaptations, states, situations, and contexts can be expected to be stronger or weaker.

Since traits and contexts (as well as adaptations) are defined as enduring or only slowly changing over time, trait-context, trait-adaptation, and adaptation-context transactions (right side of Figure 6) can be seen as symmetrical. This means that the transactional processes take place over longer timescales between variables that are defined by their long-term temporal stability (Rauthmann, 2021). This may, for example, include transactions between person variables and social relationships over the lifespan (Wrzus \& Neyer, 2016) and transactions between persons' traits and their work environment associated with long-term stable or recurring job demands (Denissen et al., 2014). A further symmetrical relation is the state-situation transaction (left side of Figure 6) because both the state and situation variables are defined as fast-changing or momentary (although short-term consistent). The transactional process can unfold over shorter time scales, such as the bidirectional dynamics between job-related stressors and psychological strains (Ford et al., 2014) or the interplay between states and daily life situations 
(Rauthmann et al., 2016). Finally, we can differentiate two asymmetrical transactions between long-term stable (trait) and short-term consistent variables (states and situations), such as the dynamic interplay between major life events and traits (Denissen et al., 2019).

The conceptualizations of trait and environment variables as well as characteristics of person-environment units do not only have consequences for the symmetry and time scale of transaction patterns, but also for the expected effect sizes: Trait-like and environment characteristics are expected to show stronger effects on state-like and adaptation-like characteristics (solid effect paths in Figure 6), whereas the reverse effects are expected to be weaker (dotted effect paths in Figure 6), but the distal transactions between traits and environments should be comparable in size. This is not fully in line with empirical findings which has so far often pointed towards stronger trait $\rightarrow$ environment than environment $\rightarrow$ trait effects (Bleidorn et al., 2018; Kandler et al., 2012; Neyer et al., 2014). The latter may be due to the fact that most measures of person characteristics are broader and more reliable than most measures of environments and that environment measures are often based on the targets' assessments of whether or not they have experienced some kind of environments (e.g., certain events). Better measures of the subjective or actual individual niches, contexts, situations, and life events (see, e.g., Bleidorn, Hopwood, Back et al., 2020; Luhmann et al., in press; Rauthmann et al., 2015) may also result in finding effects of environment variables on person characteristics (and thus on trait change on the long run) which are comparable in size to trait $\rightarrow$ environment effects, as we have proposed here (see Figure 6).

\section{Implications for Person(ality) Differences and Coherence}

We have conceptualized P-E fit as an optimal match or P-E fitting as reaching an optimal match between characteristics of persons (i.e., traits) or profiles of traits and characteristics of their environment or constellations of environmental aspects to produce the best outcome(s) for persons. P-E fit and fitting can be operationalized very differently, and the different variable-centered and person-centered approaches offered in the literatures dealing with $P-E$ fit are not interchangeable. However, the combined consideration of the different strategies to capture P-E fit can add to complementary understandings of (1) why personality differences increase, decrease, and stabilize and (2) why persons volitionally initiate specific actions, react in a specific individual way, seek, avoid, change, or create certain environments as 
well as experience the world as they perceive it. Together, we can thus derive a better sense of a stable, consistent, and unified (i.e., coherent) person(ality). This perspective on personality coherence as the extent to which personality-relevant characteristics fit with the individual environment has the potential to explain most and even harmonize conflicting empirical results. We will exemplarily highlight those seemingly conflicting findings in the following section.

\section{Question 3: What Is the Explanatory Power of Person(ality)-Environment Fit(ting)?}

P-E fit patterns and fitting mechanisms have implications for an understanding of personality stability and change, self-regulation, identity formation, well-being, and psychological interventions. Thus, we can split the third question into three subquestions: To what extent (1) do persons craft themselves a certain niche by influencing their environments, and to what extent do these environments have implications for their development; (2) does P-E fit have consequences for people's well-being, identity formation, and social standing; and (3) can psychological interventions influence P-E fit and thus person(ality) coherence?

\section{Personality Development}

The P-E fitting mechanisms, such as environment attraction (vs. avoidance), evocation, modulation, and creation (Rauthmann, 2021), may serve as (self)regulatory functions. They do not only lead to non-random associations between specific traits or profiles of traits and certain characteristics of the environment, but can also act as driving forces of personality development (Scarr, 1992). Selected, evoked, or modified environments could act to stabilize and reinforce the dispositions that have led people to those environments in the first place (Caspi, Shiner, \& Moffitt, 2005; Scarr \& McCartney, 1983). Both person(ality) $\rightarrow$ environment effects (i.e., selection and modification) and environment $\rightarrow$ person(ality) effects (i.e., socialization) act in concert and lead to both stability and change. In fact, research has already provided evidence for both increasing rank-order stability in personality trait measures (Briley \& Tucker-Drob, 2014; Roberts \& DelVecchio, 2000) and increasing (primarily genetic) variance in the same trait measures, in particular during the first third of life (Mõttus et al., 2017, 2019; Roberts et al., 2003). In other words, "as they grow, children gain more freedom and autonomy from parents and teachers, which may come along with increasing opportunities to actively shape and regulate their own development" (Kandler et al., 2019, p. 223). 
Taking both random and non-random error of measurement into account, individual differences in measures of traits have been found to be largely stable beyond age 30 and even over longer periods of time (Bleidorn et al., 2009; Kandler et al., 2010, 2013; Terracciano et al., 2006, 2010). Moreover, there is little evidence for continuously increasing trait stabilization and differences after young adulthood (Allemand et al., 2008; Mõttus et al., 2016; Viken et al., 1994). On average, however, people appear to develop towards socially adapted and functionally mature individuals (Roberts et al., 2006) until middle adulthood and then tend to show reverse trends in old age (Kandler et al., 2015). Those mean-level trends may be attributable to an evolved species-typical biological maturation process in younger ages and physiological as well as mental losses in old age (McCrae et al., 2000; McCrae \& Costa, 2008; Weiss et al., 2015).

These reversed U-shaped mean-level trends may also be attributable to individual investments in, or adaptations to, societal demands and normative expectations at a given age (Lodi-Smith \& Roberts, 2007). As individual opportunities and social demands are changing throughout the lifespan, the person(ality) may also change (Denissen et al., 2013). Some individual profiles may show better, and others worse fit to environmental demands. With increasing misfit, the tendency to adapt to the environment may increase to a certain extent (at least in healthy and selfdetermined adults) and thus the probability for change. Particularly in adulthood, social demands may set strong normative standards for being functional and successful in normative life contexts, such as doing a good job or being a good parent. Accordingly, Bleidorn et al. (2013) reported accelerated increases in measures of socially functional characteristics (e.g., agreeableness and conscientiousness) in cultures with an earlier normative timing of job role transitions. These standards may increase uniformity and thus account for mean-level trends towards social acceptance. Further, such fitting to normative demands would lead to decreasing inter-individual differences. It may then counterbalance the reinforcement of individual traits due to the tendency to pick or build fitting niches and thus account for a rather stable size of individual differences in adulthood (Mõttus et al., 2016).

Both P-E fitting mechanisms, the tendency to select or create fitting niches and the tendency to change oneself to adapt to the environment, coexist and can account for both personality stability as well as change patterns (Roberts \& Robins, 2004). For example, they imply that individual differences can become more complex 
and stable with maturation and socialization, even though change can happen with changing contextual opportunities and situational demands at any time in any age across the lifespan. If these environmental influences reflect normative pressures, we may observe specific mean-level trends towards social functionality and reduced variance due to social uniformity that counterbalance tendencies to express oneself by selecting, modifying, or creating fitting environments, which increases variance.

Although the literature suggests support for both fitting mechanisms related to personality development, no study so far has disentangled true trait change from adaptations over time. Most studies relied on the famous Big Five trait constructs, often captured with just one method (e.g., self-reports) in just one context and limited measurement occasions. Thus, we do not know much about what is changing and to what extent findings will be replicable across measurement methods. Is it the measurement of the trait, the adequate reflection of the trait (see Figure 7A), or only the trait expression in a context (or adaptation; see Figure 7B) that is changing? The systematic disentanglement of person characteristics (i.e., traits) and adaptations (i.e., characteristics of person-context units) as proposed in this synthesis and the investigation of their developmental patterns across the lifespan against the background of P-E fit(ting) patterns may allow unraveling trait from adaptation changes. Perhaps both traits and adaptations are changing, though with faster and larger change patterns for adaptations than for traits (see Figure 7C).

Beyond the aforementioned fitting mechanisms, person(ality) $\times$ environment interactions have to be taken into account because persons differ in their resources (e.g., genetic sensitivity) and opportunities for fit (e.g., autonomy, socioeconomic status, and national social policies) that moderate the stabilization and unfolding of (primarily genetic) variance in specific measures of person characteristics (Kandler et al., 2019; Tucker-Drob \& Bates, 2015). In addition, non-normative environmental influences (e.g., early loss of close people, individual promotion vs. degradation at work, or daily hassles) come to play in people's lives and may have very individual consequences. Thus, we may observe increasing individuality and inter-individual differences over time. The latter is in line with the trend of increasing differences in genetically identical twins and environmental variance in measures of traits across the lifespan (Briley \& Tucker-Drob, 2014; Kandler \& Papendick, 2017). 
Figure 7. Three potential scenarios of trait (blue line) and adaptation change (red line) in light of different person(ality)-environment fitting mechanisms

A.

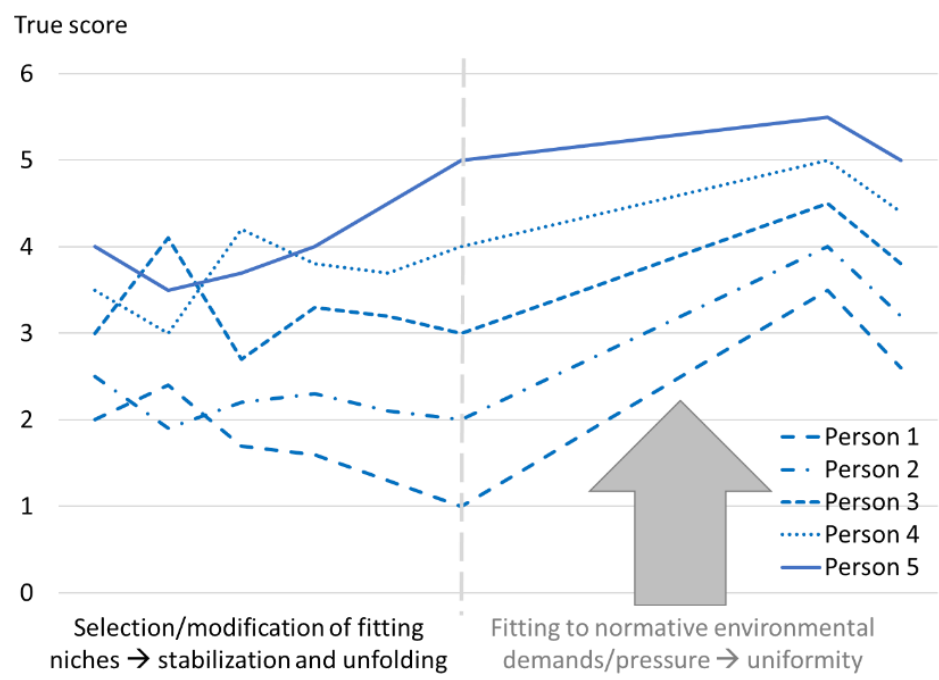

B.

True score

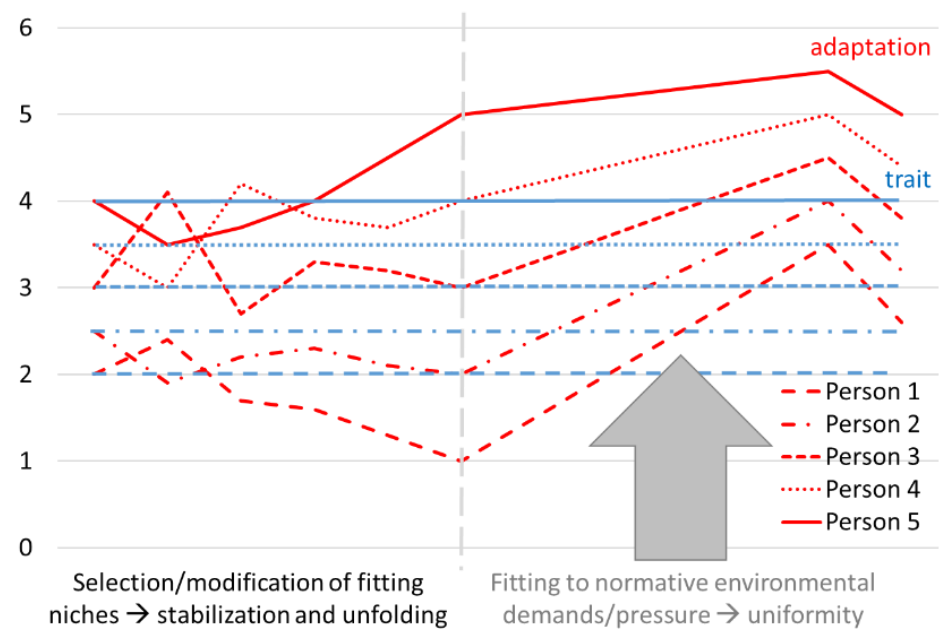

C.

True score

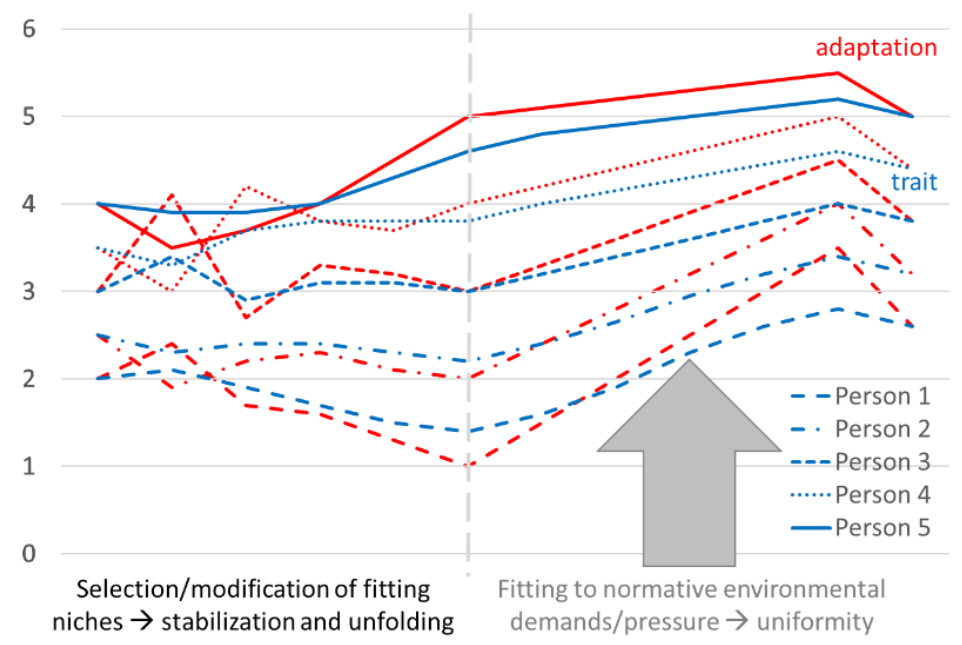


In sum, personality development can be seen as a result of at least three global P-E fitting mechanisms: (1) Amplifying person(ality)-environment transactions, leading to both increasing personality differences and stabilization (left side of Figure 7); (2) fitting to normative environmental demands, leading to social functionality and uniformity (right side of Figure 7); and (3) accumulating person(ality) $x$ environment interaction effects. The latter may be attributable to variance in persons' traits and related individual resources to deal with the same social demands or different environmental opportunities for similar persons with comparable trait profiles. In both cases, individuals have different chances to unfold their individual uniqueness with different consequences for their personality development. All these mechanisms coexist in shaping very different and unique courses of development.

\section{Well-being, Identity, and Reputation}

Persons with higher P-E fit may not only be more cross-temporally stable, consistent across contexts and situations in their trait expressions, and show less personality change, but also experience themselves as more authentic, feel more happiness in daily life, show higher self-esteem, and report higher life satisfaction. For example, living in environments matching characteristics of people is associated with higher self-esteem (Bleidorn et al., 2016) and life satisfaction (Jokela et al., 2015). Further, a higher individual fit between people's leisure interests and realization of their interests across diverse leisure activities incrementally predicted higher well-being beyond leisure engagement per se (Schulz et al., 2018). Moreover, people whose self-rated trait profiles fit a normative profile in the current social environment (Klimstra et al., 2010) or an expert-generated normative profile of a typically healthy person have been found to be "psychologically well-adjusted, had high self-esteem, good self-regulatory skills, an optimistic outlook on the world, and a clear and stable self-view", and they were "low in aggression and meanness, unlikely to exploit others, and (...) relatively immune to stress and self-sufficient" (Bleidorn, Hopwood, Ackerman et al., 2020, p. 1207).

In addition to higher adjustment and health, persons with higher P-E fit may also be perceived as more authentic by others which could make them easier to judge (Human et al., 2014, 2019). This, in turn, may affect the person's social reputation and integration (Human \& Biesanz, 2013). Given this importance of P-E fit, persons may be motivated to monitor specific fits to their environments. Such monitoring would serve as an important self-regulatory mechanism to attain higher fit 
which would, in turn, entail higher intra- and inter-personal adjustment and social integration (Rauthmann, 2021). Moreover, as P-E fitting depends on the opportunities and limitations in macro-contexts, such as geographical regions, societies, cultures, countries, or nations, the striving for P-E fit can also have implications for social and national identity (Schmader \& Sedikides, 2018) and international mobility (Oishi, 2017). An individual who does not see opportunities for individual development, identity formation, and social integration may intend to move. Thus, P-E fit(ting) may be an important mechanism to better understand mobility and migration patterns.

\section{Subjectivity and Psychological Interventions}

The individual monitoring of P-E fit may depend to some degree on a person's subjective perception of his or her own recurring, habitual, and typical feeling, striving, thinking, and acting as well as a person's psychological meaning and interpretation (e.g., valence, controllability, importance, and predictability) of major events, recurring situations, or micro- and macro-contexts (Bleidorn, Hopwood, Back et al., 2020; Luhmann et al., in press; Rauthmann et al., 2015). On the one hand, this subjectivity suggests that we need to go beyond self-reports on personality and targets' assessments of their environments. Otherwise, we cannot differentiate between "true" person and environment variables, because both are persons' perception variables (Rauthmann et al., 2015). If measures of environment variables are based on targets' subjective views on environments and hence actually are person or person-in-environment variables, we should not be surprised by findings on heritability of almost all environment characteristics (Kendler \& Baker, 2007; Turkheimer, 2000). Thus, it is not really clear what is heritable: The subjective tendency to perceive environments in an individual light or being in the actual environment. Further, it may not be surprising that recent research found evidence that psychological interventions affect personality change (Roberts et al., 2017) if almost all studies rely on self-reports. Relying only on one data source which essentially equates personality traits with self-reports (which essentially capture generalized explicit self-concepts related to trait content) leaves the question open what exactly changes: only how people see themselves, other aspects of the trait that is tapped, or all of these. Self-perceptions are one slice of traits but not the only one, and thus intervention and change studies need to employ multiple data sources and methods to holistically tap people's "whole traits." 
On the other hand, subjectivity is of course psychologically relevant. The subjective perception of oneself, the individually unique perception of environments, and the individual monitoring of P-E (mis)fits can be seen as characteristics of persons with highly unique implications for individual personality stability and change. For example, higher self-reported neuroticism has been associated with experiencing the world in a more negative light, which in turn can increase the effect of stressors and thus the development of depressive symptoms (Kandler \& Ostendorf, 2016). In terms of diathesis $\times$ stress models, the repeated or chronic exposure to stressful situations and the subjective experience of those situations as particularly stressing synergistically enhances the probability for disorder onset. This has implications for potentially fruitful intervention programs. If interventions, for instance, constitute repeated exposures to certain environments (which is the case in exposure-based cognitive behavioral psychotherapy) and/or if they include cognitive restructuring of negative self-perceptions (which is part of many therapies), then interventions may instill change in how individuals perceive themselves and the world (Abramowitz et al., 2019; Hollandt et al., 2020; Hope et al., 2010; Pull, 2007). Changes in self-reports on own characteristics and experiences are not surprising after psychotherapy. However, the more important question is to what extent (or for how long) the respective adaptations are lasting or even become part of persons' dispositional traits. If we want to know whether and to what extent a person's trait is changing after psychotherapy, we will have to rely on multi-method and multi-time data instead of just self-reports in a limited time frame.

Psychological interventions, such as in cognitive behavioral psychotherapy, may also impact subjective monitoring of P-E (mis)fit. Therefore, they could have a profound impact on the contexts persons select and modify in their daily lives and across the lifespan. These short-term changes in contexts may provide the basis for long-term change in adaptations and increase well-being. Perhaps they may also be functional for true trait change on the long run. Assessing both the actual and the subjective individual P-E (mis)fits is, in our view, an important step towards a comprehensive understanding of an individual and thus successful interventions for targeting (self-directed) development towards a stable, consistent, and unified (i.e., coherent) person(ality). 


\section{Conclusions and Final Implications for Personality Coherence}

All the considerations in this paper were based on the facts that a personality characteristic, as commonly defined, can neither be assessed with only one method (or indicator), nor within one measurement occasion, nor in an environmental vacuum. This has not only consequences for the operationalization of personality characteristics and differences, but also for the concept and operationalization of personality coherence. Table 3 provides an overview of five different perspectives on coherence (Fournier et al., 2015) and how they can be synthesized under the umbrella person(ality)-environment units and fit, as we proposed here.

The definitions of person characteristics (i.e., traits), environment characteristics (i.e., situations and contexts), and characteristics of personenvironment units (i.e., adaptations and states) in our synthesis are compatible with several models, theories, and frameworks of personality psychology, including biological, trait, interactionist, as well as dynamic system and process models. For example, our synthesis can harmonize several tenets of the Five-Factor Theory (McCrae et al., 2021), the Cognitive-Affective-Processing System model (Mischel \& Shoda, 1995), the Disposition-Adaptation-Environment model (Asendorpf \& MottiStefanidi, 2018), and the Latent-State-Trait Theory (Steyer et al., 1999, 2015).

The seven criteria to identify dispositional traits of individuals allow us to get a first insight into person(ality) differences (McCrae \& Costa, 2021). In other words, they provide a window into personality coherence in a narrow multivariate (trait-only) sense. For example, a focus can be put on the stability and consistency of one's trait profile and the trait-relevant behavioral consistency (i.e., feeling, thinking, striving, and acting) across situations and contexts. Both stability and consistency should facilitate the perception of a coherent person's acting and thus make the person easier to judge (Human \& Biesanz, 2013).

We maintain that the analysis of the degree of an individual's differentiated and integrated uniqueness and functioning (personality coherence in a broad sense) has to go beyond a trait-only perspective. Coherence may sound like a property that is genuine to persons, but as we have argued, environmental information is crucial to incorporate into our understanding of coherence. Specifically, coherence requires information about how traits are actually expressed in, or interact and transact with, individual environments. An understanding of personality coherence includes knowledge on an individual's acting in environments and experiencing the world. 
Table 3. Five perspectives of personality coherence under the umbrella of person(ality)-environment units and fit

\begin{tabular}{|c|c|c|c|c|}
\hline \multirow[b]{2}{*}{ Perspective } & \multicolumn{2}{|c|}{ Focus of analysis } & \multirow{2}{*}{$\begin{array}{l}\text { Exemplified indicators of } \\
\text { person(ality) coherence }\end{array}$} & \multirow{2}{*}{$\begin{array}{l}\text { Exemplified extension to } \\
\text { person-environment fit }\end{array}$} \\
\hline & Units & Characteristics & & \\
\hline $\begin{array}{l}\text { Person-only } \\
\text { (trait-only) }\end{array}$ & Persons & Traits & $\begin{array}{l}\text { Degree of a person's trait profile } \\
\text { stability/consistency and interrater } \\
\text { agreement/consensus }\end{array}$ & $\begin{array}{l}\text { Extent of congruence between } \\
\text { traits/profiles and } \\
\text { environments/niches to result in an } \\
\text { optimal outcome }\end{array}$ \\
\hline $\begin{array}{l}\text { Behavior-in- } \\
\text { environments- } \\
\text { only (social- } \\
\text { cognitive) }\end{array}$ & $\begin{array}{l}\text { Persons-in- } \\
\text { environments }\end{array}$ & $\begin{array}{l}\text { States and adaptations } \\
\text { (as situationalized and } \\
\text { contextualized patterns } \\
\text { of behavior) }\end{array}$ & $\begin{array}{l}\text { Extent of a unified (vs. } \\
\text { compartmentalized) configuration of } \\
\text { individual attributes/self-concept and } \\
\text { situationalized or contextualized } \\
\text { temporal stability of individual's } \\
\text { behavior }\end{array}$ & $\begin{array}{l}\text { Degree of congruence between } \\
\text { unified (vs. compartmentalized) } \\
\text { individual attributes and situations } \\
\text { (e.g., functional reactions) and/or } \\
\text { contexts (e.g., fitting roles) }\end{array}$ \\
\hline Cybernetic & $\begin{array}{l}\text { Persons and } \\
\text { persons-in- } \\
\text { environments }\end{array}$ & $\begin{array}{l}\text { Traits, states, and } \\
\text { adaptations }\end{array}$ & $\begin{array}{l}\text { Degree of horizontal goal-goal } \\
\text { congruence or vertical goal-value } \\
\text { congruence (vs. conflict) aiding goal } \\
\text { attainment }\end{array}$ & $\begin{array}{l}\text { Extent of person's dispositional } \\
\text { expressions in and adaptations to } \\
\text { their environments (i.e., situations and } \\
\text { contexts) to increase fit }\end{array}$ \\
\hline Organismic & $\begin{array}{l}\text { Persons and } \\
\text { persons-in- } \\
\text { environments }\end{array}$ & $\begin{array}{l}\text { Traits, states, and } \\
\text { adaptations }\end{array}$ & $\begin{array}{l}\text { Extent of (experienced) self-regulation } \\
\text { (vs. social regulation) in dependence } \\
\text { of limitations and opportunities of } \\
\text { autonomy }\end{array}$ & $\begin{array}{l}\text { Degree of persons' self-regulated } \\
\text { expressions, development, and } \\
\text { expansions in fitting environments }\end{array}$ \\
\hline Personological & $\begin{array}{l}\text { Persons and } \\
\text { persons-in- } \\
\text { environments }\end{array}$ & $\begin{array}{l}\text { (Self-views of) traits, } \\
\text { states, adaptations, } \\
\text { and experiences of } \\
\text { environments }\end{array}$ & $\begin{array}{l}\text { Degree of thematic richness, } \\
\text { chronological consistency, and } \\
\text { meaning making of life narratives }\end{array}$ & $\begin{array}{l}\text { Subjective monitoring of person- } \\
\text { environment fit (vs. misfit) across the } \\
\text { course of life }\end{array}$ \\
\hline
\end{tabular}


Thus, we have to focus on how characteristics of persons are interwoven with characteristics of their environments and how people themselves play an active and functional role in this interwovenness. In other words, a whole picture of an individual's uniqueness requires an integration of person and environment characteristics. This integration has been described as two different kinds of characteristics of person-environment units (states and adaptations), which include person $\times$ environment interactions and can account for the stability of individual's behavior within situations and contexts (Cervone \& Shoda, 1999; Fleeson, 2007).

Moreover, the conceptualizations of person-environment units and the mechanisms of person-environment fitting, along with their implications for personality development, identity formation, well-being, and psychological interventions, may enrich further functional sides of personality coherence, as recently outlined by Fournier (2021). An understanding of the extent to which persons volitionally initiate specific actions - evoke and manipulate social situations, select or avoid contexts, create or change their niches, or to adapt to the environment - to maximize person-environment fit and minimize misfit is compatible with and enriches cybernetic and organismic views on personality coherence (see Fournier et al., 2021, for more details). This includes, for example, the degree of autonomous selfregulation towards congruence between one's personal goals or values (e.g., shortterm goals as potential state-like and long-term values as potential adaptation-like characteristics) with one's basic or higher-order psychological motives (as potential trait-like characteristics). It may also include the degree of congruence between one's dispositions and self-directed adjustment to environments as driver of development (Deci \& Ryan, 2000; Denissen et al., 2013). Further, how and to what extent persons perceive themselves and their environments through the lens of fit monitoring is compatible with and enriches the social-cognitive and personological perspectives on coherence where a unique person possesses an integrated unified self-concept and with a differentiated, consistent, and meaning-making life story.

Taken together, we believe that personality coherence as a many-sided unity of personality (unitas multiplex; Allport, 1937) can be extended by and harmonized under the umbrella of person(ality)-environment units and fit. This work served to lay the conceptual and formal foundation upon which to base further studies into personality coherence and integrate those with existing literatures. Studying 
personality coherence as an unitas multiplex will only be possible when attending to both persons, environments, and their interplay.

\section{References}

Abramowitz, J. S., Deacon, B. J., \& Whiteside, S. P. (2019). Exposure therapy for anxiety: Principles and practice. Guilford Publications.

Allemand, M., Zimprich, D., \& Hendriks, A. A. J. (2008). Age differences in five personality domains across the life span. Developmental Psychology, 44, 758-770. https://doi.org/10.1037/0012-1649.44.3.758

Allport, G. W. (1931). What is a trait of personality? The Journal of Abnormal and Social Psychology, 25, 368-372. https://doi.org/10.1037/h0075406

Allport, G. W. (1937). Personality: A psychological interpretation. New York, NY, USA: H. Holt and Co.

Allport, G. W. (1966). Traits revisited. American Psychologist, 21, 1-10. https://doi.org/10.1037/h0023295

Asendorpf, J. B., \& Motti-Stefanidi, F. (2018). Mediated disposition-environment transactions: The DAE model. European Journal of Personality, 32, 167-185. https://doi.org/10.1002/per.2118

Baumert, A., Schmitt, M., Perugini, M., Johnson, W., Blum, G., Borkenau, P., Costantini, G., Denissen, J. J. A., Fleeson, W., Grafton, B., Jayawickreme, E., Kurzius, E., MacLeod, C., Miller, L. C., Read, S. J., Roberts, B., Robinson, M. D., Wood, D., \& Wrzus, C. (2017). Integrating personality structure, personality process, and personality development. European Journal of Personality, 31, 503-528. https://doi.org/10.1002/per.2115

Bleidorn, W., Kandler, C., Riemann, R., \& Angleitner, A. (2009). Pattern and sources of adult personality development: Growth curve analyses of the NEO-PI-R scales in a longitudinal twin study. Journal of Personality and Social Psychology, 97, 142-155. https://doi.org/10.1037/a0015434

Bleidorn, W., Klimstra, T. A., Denissen, J. J. A., Rentfrow, P. J., Potter, J., \& Gosling, S. D. (2013). Personality maturation around the world: A cross-cultural examination of socialinvestment theory. Psychological Science, 24, 2530-2540. https://doi.org/10.1177/0956797613498396

Bleidorn, W., Hopwood, C. J., Ackerman, R. A., Witt, E. A., Kandler, C., Riemann, R., Samuel, D. B., Donnellan, B. M. (2020). The healthy personality from a basic trait perspective. Journal of Personality and Social Psychology, 118, 1207-1225. http://dx.doi.org/10.1037/pspp0000231

Bleidorn, W., Hopwood, C. J., Back, M. D., Denissen, J. J. A., Hennecke, M., Jokela, M., Kandler, C., Lucas, R. E., Luhmann, M., Orth, U., Roberts, B. W., Wagner, J., Wrzus, C., \& Zimmermann, J. (2020). Longitudinal Experience-Wide Association Studies (LEWAS) - A framework for studying personality change. European Journal of Personality, 34, 285-300. https://doi.org/10.1002/per.2247

Bleidorn, W., Hopwood, C. J., \& Lucas, R. E. (2018). Life events and personality change. Journal of Personality, 86, 83-96. https://doi.org/10.1111/jopy.12286

Bleidorn, W., Schönbrodt, F., Gebauer, J. E., Rentfrow, P. J., Potter, J., \& Gosling, S. D. (2016). To live among like-minded others: Exploring the links between person-city personality fit and self-esteem. Psychological Science, 27, 419-427. https://doi.org/10.1177/0956797615627133 
Blum, G. S., Rauthmann, J. F., Göllner, R., Lischetzke, T., \& Schmitt, M. (2018). The Nonlinear Interaction of Person and Situation (NIPS) Model: Theory and empirical evidence. European Journal of Personality, 33, 286-305. https://doi.org/10.1002/per.2138

Briley, D. A., Livengood, J., \& Derringer, J. (2018). Behaviour genetic frameworks of causal reasoning for personality psychology. European Journal of Personality, 32, 202-220. https://doi.org/10.1002/per.2153

Briley, D. A., \& Tucker-Drob, E. M. (2014). Genetic and environmental continuity in personality development: A meta-analysis. Psychological Bulletin, 140, 1303-1331. https://doi.org/10.1037/a0037091

Bronfenbrenner, U. (1979). The ecology of human development: experiments by nature and design. Harvard University Press.

Campbell, D. T., \& Fiske, D. W. (1959). Convergent and discriminant validation by the multitrait-multimethod matrix. Psychological Bulletin, 56, 81-105. https://doi.org/10.1037/h0046016

Caspi, A., Roberts, B.W., \& Shiner, R. L. (2005). Personality development: Stability and change. Annual Review of Psychology, 56, 453-484. https://doi.org/10.1146/annurev.psych.55.090902.141913

Cervone, D., \& Shoda, Y. (1999). Beyond traits in the study of personality coherence. Current Directions in Psychological Science, 8, 27-32. https://doi.org/10.1111/1467$\underline{8721.00007}$

Chaplin, W. F., John, O. P., \& Goldberg, L. R. (1988). Conceptions of states and traits: dimensional attributes with ideals as prototypes. Journal of Personality and Social Psychology, 54, 541-557. https://doi.org/10.1037//0022-3514.54.4.541

Costantini, G., Epskamp, S., Borsboom, D., Perugini, M., Mõttus, R., Waldorp, L. J., \& Cramer, A. O. J. (2015). State of the aRt personality research: A tutorial on network analysis of personality data in R. Journal of Research in Personality, 54, 13-29. https://doi.org/10.1016/j.jrp.2014.07.003

Courvoisier, D. S., Nussbeck, F. W., Eid, M., Geiser, C., \& Cole, D. A. (2008). Analyzing the convergent and discriminant validity of states and traits: Development and applications of multimethod latent state-trait models. Psychological Assessment, 20, 270-280. https://doi.org/10.1037/a0012812

Cronbach, L. J., \& Meehl, P. E. (1955). Construct validity in psychological tests. Psychological Bulletin, 52, 281-302. https://doi.org/10.1037/h0040957

Danvers, A. F., Wundrack, R., \& Mehl, M. (2020). Equilibria in personality states: A conceptual primer for dynamics in personality states. European Journal of Personality, 34, 999-1016. https://doi.org/10.1002/per.2239

Deci, E. L., \& Ryan, R. M. (2000). The "what" and "why" of goal pursuits: Human needs and the self-determination of behavior. Psychological Inquiry, 11, 227-268. https://doi.org/10.1207/S15327965PLI1104 01

Deci, E. L., \& Ryan, R. M. (2012). Motivation, personality, and development within embedded social contexts: An overview of self-determination theory. In R. M. Ryan (Ed.), Oxford Handbook of Human Motivation (pp. 85-107). Oxford University Press. http://dx.doi.org/10.1093/oxfordhb/9780195399820.013.0006

Denissen, J. J. A., Luhmann, M., Chung, J. M., \& Bleidorn, W. (2019). Transactions between life events and personality traits across the adult lifespan. Journal of Personality and Social Psychology, 116, 612-633. https://doi.org/10.1037/pspp0000196

Denissen, J. J. A., Ulferts, H., Lüdtke, O., Muck, P. M., \& Gerstorf, D. (2014). Longitudinal transactions between personality and occupational roles: A large and heterogeneous 
study of job beginners, stayers, and changers. Developmental Psychology, 50, 19311942. http://dx.doi.org/10.1037/a0036994

Denissen, J. J. A., Van Aken, M. A. G., Penke, L., \& Wood, D. (2013). Self-regulation underlies temperament and personality: An integrative developmental framework. Child Development Perspectives, 7, 255-260. https://doi.org/10.1111/cdep.12050

DeYoung, C. G. (2015). Cybernetic Big Five Theory. Journal of Research in Personality, 56, 33-58. https://doi.org/10.1016/i.jrp.2014.07.004

Dunlop, W. L. (2015). Contextualized personality, beyond traits. European Journal of Personality, 29, 310-325. https://doi.org/10.1002/per.1995

Edwards, J. R., Caplan, R. D., \& Harrison, R. V. (1998). Person-environment fit theory: Conceptual foundations, empirical evidence, and directions for future research. In C. L. Cooper (Ed.), Theories of organizational stress (pp. 28-67). Oxford University Press.

Eid, M., Lischetzke, T., Nussbeck, F. W., \& Trierweiler, L. I. (2003). Separating trait effects from trait-specific method effects in multitrait-multimethod models: A multiple-indicator CT-C(M-1) model. Psychological Methods, 8, 38-60. http://dx.doi.org/10.1037/1082989X.8.1.38

Ellis, B. J., Boyce, W. T., Belsky, J., Bakermans-Kranenburg, M. J., \& Van IJzendoorn, M. H. (2011). Differential susceptibility to the environment: An evolutionaryneurodevelopmental theory. Development and Psychopathology, 23, 7-28. https://doi.org/10.1038/npp.2015.294

Epstein, S. (1979). The stability of behaviour: I. On predicting most of the people much of the time. Journal of Personality and Social Psychology, 37, 1097-1126. https://doi.org/10.1037/0022-3514.37.7.1097

Epstein, S. (1980). The stability of behaviour: II. Implications for psychological research. American Psychologist, 35, 790-806. https://doi.org/10.1037/0003-066X.35.9.790

Fajkowska, M. (2018), Personality traits: hierarchically organized systems. Journal of Personality, 86, 36-54. https://doi.org/10.1111/jopy.12314

Fetvadjiev, V. H., \& He, J. (2019). The longitudinal links of personality traits, values, and wellbeing and self-esteem: A five-wave study of a nationally representative sample. Journal of Personality and Social Psychology, 117, 448-464.

https://doi.org/10.1037/pspp0000212

Fleeson, W. (2001). Toward a structure- and process-integrated view of personality: Traits as density distribution of states. Journal of Personality and Social Psychology, 80, 10111027. https://doi.org/10.1037/0022-3514.80.6.1011

Fleeson, W. (2007). Situation-based contingencies underlying trait-content manifestation in behavior. Journal of Personality, 75, 825-861. https://doi.org/10.1111/j.14676494.2007.00458.x

Fleeson, W., \& Jayawickreme, E. (2015). Whole Trait Theory. Journal of Research in Personality, 56, 82-92. https://doi.org/10.1016/j.jrp.2014.10.009

Ford, M. T., Matthews, R. A., Wooldridge, J. D., Mishra, V., Kakar, U. M., \& Strahan, S. R. (2014). How do occupational stressor-strain effects vary with time? A review and metaanalysis of the relevance of time lags in longitudinal studies. Work \& Stress, 28, 9-30. https://doi.org/10.1080/02678373.2013.877096

Fournier, M. A. (2021). Integrative processes and personality coherence across levels of functioning. In: J. F. Rauthmann (ed.), Handbook of Personality Dynamics and Processes (pp. 405-423). Elsevier Academic Press. https://doi.org/10.1016/B978-0-12813995-0.00017-0 
Fournier, M. A., Di Domenico, S. I., Weststrate, N. M., Quitasol, M. N., \& Dong, M. (2015). Toward a unified science of personality coherence. Canadian Psychology, 56, 253-262. https://dx.doi.org/10.1037/cap0000022

Fraley, C., \& Roberts, B. W. (2005). Patterns of continuity: A dynamic model for conceptualizing the stability of individual differences in psychological constructs across the life course. Psychological Review, 112, 60-74. https://doi.org/10.1037/0033295X.112.1.60

Funder, D. C. (1991). Global traits: A neo-Allportian approach to personality. Psychological Science, 2, 31-39. https://doi.org/10.1111/j.1467-9280.1991.tb00093.x

Geiser, C., Götz, T., Preckel, F., \& Freund, P. A. (2017). States and traits: Theories, models, and assessment. European Journal of Psychological Assessment, 33, 219-223. https://doi.org/10.1027/1015-5759/a000413

Geiser, C., Litson, K., Bishop, J., Keller, B. T., Burns, G. L., Servera, M., \& Shiffman, S. (2015). Analyzing person, situation and person $\times$ situation interaction effects: Latent state-trait models for the combination of random and fixed situations. Psychological Methods, 20, 165-192. https://doi.org/10.1037/met0000026

Geiser, C., \& Lockhart, G. (2012). A comparison of four approaches to account for method effects in latent state-trait analyses. Psychological Methods, 17, 255-283. http://dx.doi.org/10.1037/a0026977

Geukes, K., Nestler, S., Hutteman, R., Küfner, A. C. P., \& Back, M. D. (2017). Trait personality and state variability: Predicting individual differences in within- and crosscontext fluctuations in affect, self-evaluations, and behavior in everyday life. Journal of Research in Personality, 69, 124-138. http://dx.doi.org/10.1016/.j.jp.2016.06.003

Hamaker, E. L., Nesselroade, J. R., \& Molenaar, P. C. M. (2007). The integrated trait-state model. Journal of Research in Personality, 41, 295-315. http://dx.doi.org/10.1016/j.jrp.2006.04.003

Henry, S., \& Mõttus, R. (2020) Traits and Adaptations: A Theoretical Examination and New Empirical Evidence. European Journal of Personality, 34, 265-284. https://doi.org/10.1002/per.2248

Hintz, F., Geiser, C., \& Shiffman, S. (2019). A latent state-trait model for analyzing states, traits, situations, method effects, and their interactions. Journal of Personality, 87, 434454. https://doi.org/10.1111/jopy. 12400

Hollandt, M., Wroblewski, A., Yang, Y., Ridderbusch, I. C., Kircher, T., Hamm, A. O., Straube, B., \& Richter, J. (2020). Facilitating translational science in anxiety disorders by adjusting extinction training in the laboratory to exposure-based therapy procedures. Translational Psychiatry, 10, 110. https://doi.org/10.1038/s41398-020-0786-x

Horstmann, K. T., \& Ziegler, M. (2020). Assessing personality states: What to consider when constructing personality state measures. European Journal of Personality, 34, 10371059. https://doi.org/10.1002/per.2266

Hoff, K. A., Song, Q. C., Einarsdóttir, S., Briley, D. A., \& Rounds, J. (2020). Developmental structure of personality and interests: A four-wave, 8-year longitudinal study. Journal of Personality and Social Psychology, 118, 1044-1064. https://doi.org/10.1037/pspp0000228

Hope, D. A., Burns, J. A., Hayes, S. A., Herbert, J. D., \& Warner, M. D. (2010). Automatic thoughts and cognitive restructuring in cognitive behavioral group therapy for social anxiety disorder. Cognitive Therapy and Research, 34, 1-12. https://doi.org/10.1007/s10608-007-9147-9 
Hoyt, W. T. (2000). Rater bias in psychological research: When is it a problem and what can we do about it? Psychological Methods, 5, 64-86. https://doi.org/10.1037//1082989X.5.1.64

Human, L. J., \& Biesanz, J. C. (2013). Targeting the good target: An integrative review of the characteristics and consequences of being accurately perceived. Personality and Social Psychology Review, 17, 248-272. https://doi.org/10.1177/1088868313495593

Human, L. J., Biesanz, J. C., Finseth, S. M., Pierce, B., \& Le, M. (2014). To thine own self be true: Psychological adjustment promotes judgeability via personality-behaviour congruence. Journal of Personality and Social Psychology, 106, 286-303. http://dx.doi.org/10.1037/a0034860

Human, L. J., Mignault, M.-C., Biesanz, J. C., \& Rogers, K. H. (2019). Why are well-adjusted people seen more accurately? The role of personality-behavior congruence in naturalistic social settings. Journal of Personality and Social Psychology, 117, 465-482. http://dx.doi.org/10.1037/pspp0000193

Humberg, S., Nestler, S., \& Back, M. D. (2019). Response surface analysis in personality and social psychology: Checklist and clarifications for the case of congruence hypotheses. Social Psychological and Personality Science, 10, 409-419. https://doi.org/10.1177/1948550618757600

Jokela, M., Bleidorn, W., Lamb, M. E., Gosling, S. D., \& Rentfrow, P. J. (2015). Geographically varying associations between personality and life satisfaction in the London metropolitan area. Proceedings of the National Academy of Sciences, 112, 725730. https://doi.org/10.1073/pnas.1415800112

Kandler, C. (2012). Knowing your personality is knowing its nature: The role of information accuracy of peer assessments for heritability estimates of temperamental and personality traits. Personality and Individual Differences, 53, 387-392. https://doi.org/10.1016/i.paid.2012.01.004

Kandler, C., Bleidorn, W., Riemann, R., Angleitner, A., \& Spinath, F. M. (2011). The genetic links between the Big Five personality traits and general interest domains. Personality and Social Psychology Bulletin, 37, 1633-1643.

http://dx.doi.org/10.1177/0146167211414275

Kandler, C., Bleidorn, W., Riemann, R., Angleitner, A., \& Spinath, F. M. (2012). Life events as environmental states and genetic traits and the role of personality: A longitudinal twin study. Behavior Genetics, 42, 57-72. http://dx.doi.org/10.1007/s10519-011-9491-0

Kandler, C., Bleidorn, W., Riemann, R., Spinath, F. M., Thiel, W., \& Angleitner, A. (2010). Sources of cumulative continuity in personality: A longitudinal multiple-rater twin study. Journal of Personality and Social Psychology, 98, 995-1008. http://dx.doi.org/10.1037/a0019558

Kandler, C., Kornadt, A. E., Hagemeyer, B., \& Neyer, F. J. (2015). Patterns and sources of personality development in old age. Journal of Personality and Social Psychology, 109, 175-191. https://doi.org/10.1037/pspp0000028

Kandler, C., \& Ostendorf, F. (2016). Additive and synergetic contributions of neuroticism and life events to depression and anxiety in women. European Journal of Personality, 30, 390-405. https://doi.org/10.1002/per.2065

Kandler, C., \& Papendick, M. (2017). Behavior genetics and personality development: A methodological and meta-analytic review. In: J. Specht (ed.), Personality Development across the Lifespan (pp. 473-495). Elsevier Academic Press. https://doi.org/10.1016/B978-0-12-804674-6.00029-6

Kandler, C., \& Piepenburg, A. (2020). Leisure interests and engagement: Distinct dispositions or only expressions of personality traits? Journal of Individual Differences, 41, 101-109. https://doi.org/10.1027/1614-0001/a000308 
Kandler, C., Riemann, R., \& Angleitner, A. (2013). Patterns and sources of continuity and change of energetic and temporal aspects of temperament in adulthood: A longitudinal twin study of self- and peer reports. Developmental Psychology, 49, 1739-1753. http://dx.doi.org/10.1037/a0030744

Kandler, C., Waaktaar, T., Mõttus, R., Riemann, R., \& Torgersen, S. (2019). Unravelling the interplay between genetic and environmental contributions in the unfolding of personality differences from early adolescence to young adulthood. European Journal of Personality, 33, 221-244. https://doi.org/10.1002/per.2189

Kandler, C., Zapko-Willmes, A., Richter, J., \& Riemann, R. (2021). Synergistic and dynamic genotype-environment interplays in the development of personality differences. In: J. F. Rauthmann (ed.), The Handbook of Personality Dynamics and Processes (pp. 155-181). Elsevier Academic Press. https://doi.org/10.1016/B978-0-12-813995-0.00007-8

Kandler, C., Zimmermann, J., \& McAdams, D. P. (2014). Core and surface characteristics for the description and theory of personality differences and development. European Journal of Personality, 28, 231-243. https://doi.org/10.1002/per.1952

Kendler, K. S., \& Baker, J. H. (2007). Genetic influences on measures of the environment: A systematic review. Psychological Medicine, 37, 615-626. https://doi.org/10.1017/S0033291706009524

Klimstra, T. A., Luyckx, K., Hale, W. W., Goossens, L. \& Meeus, W. H. J. (2010), Longitudinal associations between personality profile stability and adjustment in college students: Distinguishing among overall stability, distinctive stability, and within-time normativeness. Journal of Personality, 78, 1163-1184. https://doi.org/10.1111/j.1467$\underline{6494.2010 .00646 . x}$

Kraemer, H. C., Measelle, J. R., Ablow, J. C., Essex, M. J., Boyce, W. T., \& Kupfer D. J. (2003). A new approach to integrating data from multiple informants in psychiatric assessment and research: mixing and matching contexts and perspectives. American Journal of Psychiatry, 160,1566-1577. https://doi.org/10.1176/appi.ajp.160.9.1566

Kristof-Brown, A. L., \& Guay, R. P. (2011). Person-environment fit. In S. Zedeck (Ed.), American Psychological Association handbook of industrial and organizational psychology (Vol. 3, pp. 3-50). American Psychological Association.

Leising, D., Scharloth, J., Lohse, O., \& Wood, D. (2014). What Types of Terms Do People Use When Describing an Individual's Personality? Psychological Science, 25, 17871794. https://doi.org/10.1177/0956797614541285

Lodi-Smith, J., \& Roberts, B. W. (2007). Social investment and personality: A meta-analysis of the relationship of personality traits to investment in work, family, religion, and volunteerism. Personality and Social Psychology Review, 11, 68-86. https://doi.org/10.1177/1088868306294590

Low, K. S. D., Yoon, M., Roberts, B. W., \& Rounds, J. (2005). The stability of vocational interests from early adolescence to middle adulthood: A quantitative review of longitudinal studies. Psychological Bulletin, 131, 713-737. https://doi.org/10.1037/00332909.131.5.713

Luhmann, M., Fassbender, I., Alcock, M., \& Haehner, P. (in press). A dimensional taxonomy of perceived characteristics of major life events. Journal of Personality and Social Psychology, https://doi.org/10.1037/pspp0000291

Lukaszewski, A. W., Lewis, D. M. G., Durkee, P. K., Sell, A. N., Sznycer, D., and Buss, D. M. (2020). An adaptationist framework for personality science. European Journal of Personality, 34, 1151-1174. https://doi.org/10.1002/per.2292

McAdams, D. P. (2013). The psychological self as actor, agent, and author. Perspectives on Psychological Science, 8, 272-295. https://doi.org/10.1177/1745691612464657 
McAdams, D. P. (2015). The art and science of personality development. Guilford.

McAdams, D. P., \& Pals, J. (2006). A new Big Five: Fundamental principles for an integrative science of personality. American Psychologist, 61, 204-217.

https://doi.org/10.1037/0003-066X.61.3.204

McCrae, R. R. (2009). The physics and chemistry of personality. Theory \& Psychology, 19, 670-687. https://doi.org/10.1177/0959354309341928

McCrae, R. R., \& Costa, P. T., Jr. (2008). The Five-Factor Theory of personality. In O. P. John, R. W. Robins, \& L. A. Pervin (Eds.). Handbook of personality: Theory and research (pp. 159-181). (3rd ed.). Guilford.

McCrae, R. R., \& Costa, P. T. (2021). Understanding persons: From Stern's personalistics to Five-Factor Theory. Personality and Individual Differences, 169, 109784. https://doi.org/10.1016/i.paid.2020.109816

McCrae, R. R., Costa, P. T., Jr., Ostendorf, F., Angleitner, A., Hřebíčková, M., Avia, M. D., Sanz, J., Sánchez-Bernardos, M. L., Kusdil, M. E., Woodfield, R., Saunders, P. R., \& Smith, P. B. (2000). Nature over nurture: Temperament, personality, and life span development. Journal of Personality and Social Psychology, 78, 173-186. https://doi.org/10.1037/0022-3514.78.1.173

McCrae, R. R., De Bolle, M., Löckenhoff, C. E., \& Terracciano, A. (2021). Lifespan trait development: Toward an adequate theory of personality. In: J. F. Rauthmann (ed.), The Handbook of Personality Dynamics and Processes (pp. 621-641). Elsevier Academic Press. https://doi.org/10.1016/B978-0-12-813995-0.00023-6

McCrae, R. R., \& Mõttus, R. (2019). What personality scales measure: A new psychometrics and its implications for theory and assessment. Current Directions in Psychological Science, 28, 415-420. https://doi.org/10.1177/0963721419849559

McCrae, R. R., \& Sutin, A. R. (2018). A Five-Factor Theory perspective on causal analysis. European Journal of Personality, 32, 151-166. https://doi.org/10.1002/per.2134

Mischel, W. (1968). Personality and assessment. Wiley.

Mischel, W., \& Shoda, Y. (1995). A cognitive-affective system theory of personality: Reconceptualizing situations, dispositions, dynamics, and invariance in personality structure. Psychological Review, 102, 246-268. http://dx.doi.org/10.1037/0033295X.102.2.246

Molenaar, P. C. M., Sinclair, K. O., Rovine, M. J., Ram, N., \& Corneal, S. E. (2009). Analyzing developmental processes on an individual level using nonstationary time series modeling. Developmental Psychology, 45, 260-271.

https://doi.org/10.1037/a0014170

Mõttus, R., Allik, J., Hřebíčková, M., Kööts-Ausmees, L., \& Realo, A. (2016). Age differences in the variance of personality characteristics. European Journal of Personality, 30, 4-11 https://doi.org/10.1002/per.2036

Mõttus, R., Briley, D., Zheng, A., Mann, F. D., Engelhardt, L. E., Tackett, J. L., Harden, K. P., \& Tucker-Drob, E. M. (2019). Kids becoming less alike: A behavioral genetic analysis of developmental increases in personality variance from childhood to adolescence. Journal of Personality and Social Psychology, 117, 635-658.

https://doi.org/10.1037/pspp0000194

Mõttus, R., Kandler, C., Bleidorn, W., Riemann, R., \& McCrae, R. R. (2017). Personality traits below facets: The consensual validity, longitudinal stability, heritability, and utility of personality nuances. Journal of Personality and Social Psychology, 112, 474-490. http://dx.doi.org/10.1037/pspp0000100

Mõttus, R., Sinick, J., Terracciano, A., Hřebíčková, M., Kandler, C., Ando, J., Mortensen, E. L., Colodro-Conde, L., \& Jang, K. L. (2019). Personality characteristics below facets: A 
replication and meta-analysis of cross-rater agreement, rank-order stability, heritability and utility of personality nuances. Journal of Personality and Social Psychology, 117, e35-e50. http://dx.doi.org/10.1037/pspp0000202

Mõttus, R., Soto, C. J., \& Slobodskaya, H. R. (2017). Are all kids alike? The magnitude of individual differences in personality characteristics tends to increase from early childhood to early adolescence. European Journal of Personality, 31, 313-328. https://doi.org/10.1002/per.2107

Muchinsky, P. M., \& Monahan, C. J. (1987). What is person-environment congruence? Supplementary versus complementary models of fit. Journal of Vocational Behavior, 31, 268-277. https://doi.org/10.1016/0001-8791(87)90043-1

Nestler, S., Humberg, S., \& Schönbrodt, F. D. (2019). Response surface analysis with multilevel data: Illustration for the case of congruence hypotheses. Psychological Methods, 24, 291-308. https://doi.org/10.1037/met0000199

Neyer, F. J., Mund, M., Zimmermann, J., \& Wrzus, C. (2014). Personality-relationship transactions revisited. Journal of Personality, 82, 539-550. https://doi.org/10.1111/jopy.12063

Oishi, S. (2010). The psychology of residential mobility: Implications for the self, social relationships, and well-being. Perspectives on Psychological Science, 5, 5-21. https://doi.org/10.1177/1745691609356781

Ormel, J., VonKorff, M., Jeronimus, B. F., \& Riese, H. (2017). Set-Point Theory and personality development: Reconciliation of a paradox. In J. Specht (Ed.), Personality development across the lifespan (p. 117-137). Elsevier Academic Press. https://doi.org/10.1016/B978-0-12-804674-6.00009-0

Pedhazur, E. J., \& Schmelkin, L. P. (1991). Measurement, design, and analysis: An integrated approach. Lawrence Erlbaum Associates.

Pull, C. B. (2007). Combined pharmacotherapy and cognitive-behavioural therapy for anxiety disorders. Current Opinion in Psychiatry, 20, 30-35. https://doi.org/10.1097/YCO.0b013e3280115e52

Rauthmann, J.F. (2015). Structuring situational information: A road map of the multiple pathways to different situational taxonomies. European Psychologist, 20, 176-189. https://doi.org/10.1027/1016-9040/a000225

Rauthmann, J. F. (2021). Capturing Interactions, Correlations, Fits, and Transactions: A Person-Environment Relations Model. In: J. F. Rauthmann (ed.), Handbook of Personality Dynamics and Processes (pp. 427-522). Elsevier Academic Press. https://doi.org/10.1016/B978-0-12-813995-0.00018-2

Rauthmann, J.F., Gallardo-Pujol, D., Guillaume, E.M., Todd, E., Nave, C.S., Sherman, R.A., Ziegler, M., Jones, A.B. \& Funder, D.C. (2014). The Situational Eight DIAMONDS: A taxonomy of major dimensions of situation characteristics. Journal of Personality and Social Psychology, 107, 677-719. https://doi.org/10.1037/a0037250

Rauthmann, J. F., Jones, A. B., \& Sherman, R. A. (2016). Directionality of person-situation transactions: Are there spillovers among and between situation experiences and personality states? Personality and Social Psychology Bulletin, 42, 893-909. https://doi.org/10.1177/0146167216647360

Rauthmann, J. F., Sherman, R. A., Nave, C. S., \& Funder, D. C. (2015). Personality-driven situation experience, contact, and construal: How people's personality traits predict characteristics of their situations in daily life. Journal of Research in Personality, 55, 98111. https://doi.org/10.1016/i.jrp.2015.02.003

Rauthmann, J. F., Sherman, R. A., \& Funder, D. C. (2020). The Oxford Handbook on Psychological Situations. Oxford University Press. 
Reese, E., Haden, C. A., Baker-Ward, L., Bauer, P., Fivush, R., \& Ornstein, P. A. (2011). Coherence of personal narratives across the lifespan: A multidimensional model and coding method. Journal of Cognition and Development, 12, 424-462. http://dx.doi.org/10.1080/15248372.2011.587854

Revelle, W. (1983). Factors are fictions, and other comments on individuality theory. Journal of Personality, 51, 707-714. https://doi.org/10.1111/j.1467-6494.1983.tb00875.x

Roberts, B. W. (2018). A revised sociogenomic model of personality traits. Journal of Personality, 86, 23-35. https://doi.org/10.1111/jopy.12323

Roberts, B. W., Caspi, A., \& Moffitt, T. E. (2003). Work experiences and personality development in young adulthood. Journal of Personality and Social Psychology, 84, 582-593. https://doi.org/10.1037/0022-3514.84.3.582

Roberts, B. W., \& DelVecchio, W. F. (2000). The rank-order consistency of personality traits from childhood to old age: A quantitative review of longitudinal studies. Psychological Bulletin, 126, 3-25. https://doi.org/10.1037/0033-2909.126.1.3

Roberts, B. W., \& Jackson, J. J. (2008). Sociogenomic personality psychology. Journal of Personality, 76, 1523-1544. https://doi.org/10.1111/j.1467-6494.2008.00530.x

Roberts, B. W., \& Robins, R. W. (2004). A longitudinal study of person-environment fit and personality development. Journal of Personality, 72, 89-110.

https://doi.org/10.1111/j.0022-3506.2004.00257.x

Roberts, B. W., Walton, K. E., \& Viechtbauer, W. (2006). Patterns of mean-level change in personality traits across the life course: A meta-analysis of longitudinal studies.

Psychological Bulletin, 132, 1-25. https://doi.org/10.1037/0033-2909.132.1.1

Robins, R. W., Caspi, A., \& Moffitt, T. E. (2000). Two personalities, one relationship: Both partners' personality traits shape the quality of their relationship. Journal of Personality and Social Psychology, 79, 251-259. http://dx.doi.org/10.1037//0022-3514.79.2.251

Scarr, S. (1992). Developmental theories for the 1990s: Development and individual differences. Child Development, 63, 1-19. https://doi.org/10.1111/j.14678624.1992.tb03591.x

Scarr, S., \& McCartney, K. (1983). How people make their own environments: A theory of genotype $\rightarrow$ environment effects. Child Development, 54, 424-435. https://doi.org/10.2307/1129703

Schermelleh-Engel, K., Keith, N., Moosbrugger, H., \& Hodapp, V. (2004). Decomposing person and occasion-specific effects: An extension of Latent State-Trait (LST) theory to Hierarchical LST models. Psychological Methods, 9, 198-219. https://doi.org/10.1037/1082-989X.9.2.198

Schmader, T., \& Sedikides, C. (2018). State authenticity as fit to environment: The implications of social identity for fit, authenticity, and self-segregation. Personality and Social Psychology Review, 22, 228-259. https://doi.org/10.1177/1088868317734080

Schulz, P., Schulte, J., Raube, S., Disouky, H., \& Kandler, C. (2018). The role of leisure interest and engagement for subjective well-being. Journal of Happiness Studies, 19, 1135-1150. http://dx.doi.org/10.1007/s10902-017-9863-0

Shiner, R. L., \& Caspi, A. (2003). Personality differences in childhood and adolescence: Measurement, development, and consequences. Journal of Child Psychology and Psychiatry, 44, 2-32. http://dx.doi.org/10.1111/1469-7610.00101

Smaldino, P. E. (2020). How to translate a verbal theory into a formal model. Social Psychology, 51, 207-218. https://doi.org/10.1027/1864-9335/a000425

Stern, W. (1935). On the nature and structure of character. Character and Personality, 3, 270-289. https://onlinelibrary.wiley.com/doi/pdf/10.1111/j.1467-6494.1935.tb02011.x 
Steyer. R. (1989). Models of classical psychometric test theory as stochastic measurement models: Representation. uniqueness, meaningfulness. identifiability, and testability. Methodika, 3, 25-60.

Steyer, R., Mayer, A., Geiser, C., \& Cole, D. A. (2015). A theory of states and traits - revised. Annual Review of Clinical Psychology, 11, 71-98. http://dx.doi.org/10.1146/annurevclinpsy-032813-153719

Steyer, R., Schmitt, M., \& Eid, M. (1999). Latent state-trait theory and research in personality and individual differences. European Journal of Personality, 13, 389-408. https://doi.org/10.1002/(SICI)1099-0984(199909/10)13:5<389::AID-PER361>3.0.CO;2-A

Stoll, G., Einarsdóttir, S., Song, Q. C., Ondish, P., Sun, J. J., \& Rounds, J. (2020). The roles of personality traits and vocational interests in explaining what people want out of life. Journal of Research in Personality, 86, [103939]. https://doi.org/10.1016/j.jrp.2020.103939

Stoll, G., Rieger, S., Lüdtke, O., Nagengast, B., Trautwein, U., \& Roberts, B. W. (2017). Vocational interests assessed at the end of high school predict life outcomes assessed 10 years later over and above IQ and Big Five personality traits. Journal of Personality and Social Psychology, 113, 167-184. https://doi.org/10.1037/pspp000011

Terracciano, A., Costa, P. T., Jr., \& McCrae, R. R. (2006). Personality plasticity after age 30. Personality and Social Psychology Bulletin, 32, 999-1009. https://doi.org/10.1177/0146167206288599

Terracciano, A., McCrae, R. R., \& Costa, P. T., Jr. (2010). Intra-individual change in personality stability and age. Journal of Research in Personality, 44, 31-37. https://doi.org/10.1016/j.jrp.2009.09.006

Tucker-Drob, E. M., \& Bates, T. C. (2015). Large cross-national differences in gene $\times$ socioeconomic status interaction on intelligence. Psychological Science, 27, 138-149. https://doi.org/10.1177/0956797615612727

Turkheimer, E. (2000). Three laws of behavior genetics and what they mean. Current Directions in Psychological Science, 9, 160-164. https://doi.org/10.1111/14678721.00084

Usslepp, N, Hübner, N, Stoll, G, Spengler, M, Trautwein, U, \& Nagengast, B. (2020). RIASEC interests and the Big Five personality traits matter for life success-But do they already matter for educational track choices? Journal of Personality, 88, 1007-1024. https://doi.org/10.1111/jopy.12547

Vazire, S. (2010). Who knows what about a person? The self-other knowledge asymmetry (SOKA) model. Journal of Personality and Social Psychology, 98, 281-300. https://doi.org/10.1037/a0017908

Vazire, S., \& Mehl, M. R. (2008). Knowing me, knowing you: The accuracy and unique predictive validity of self-ratings and other-ratings of daily behavior. Journal of Personality and Social Psychology, 95, 1202-1216. https://doi.org/10.1037/a0013314

Viken, R. J., Rose, R. J., Kaprio, J., \& Koskenvuo, M. (1994). A developmental genetic analysis of adult personality: Extraversion and neuroticism from 18 to 59 years of age. Journal of Personality and Social Psychology, 66, 722-730. https://doi.org/10.1037/0022-3514.66.4.722

Wagner, J., Orth, U., Bleidorn, W., Hopwood, C. J., \& Kandler, C. (2020). Towards an integrative model of sources of personality stability and change. Current Directions in Psychological Science, 29, 438-444. https://doi.org/10.1177/0963721420924751

Watson, D., Klohnen, E. C., Casillas, A., Simms, E. N., Haig, J., \& Berry, D. S. (2004). Match makers and deal breakers: Analyses of assortative mating in newlywed couples. Journal of Personality, 72, 1029-1068. http://dx.doi.org/10.1111/i.0022-3506.2004.00289.x 
Weiss, A., Bates, T. C., \& Luciano, M. (2008). Happiness Is a Personal(ity) Thing: The Genetics of Personality and Well-Being in a Representative Sample. Psychological Science, 19, 205-210. https://doi.org/10.1111/j.1467-9280.2008.02068.x

Weiss, A., \& King, J. E. (2015). Great ape origins of personality maturation and sex differences: A study of orangutans and chimpanzees. Journal of Personality and Social Psychology, 108, 648-664. https://doi.org/10.1037/pspp0000022

Wilt, J., \& Revelle, W. (2015). Affect, behaviour, cognition and desire in the Big Five: An analysis of item content and structure. European Journal of Personality, 29, 478-497. http://dx.doi.org/10.1002/per.2002

Wrzus, C., \& Neyer, F. J. (2016). Co-development of personality and friendships across the lifespan: An empirical review on selection and socialization. European Psychologist, 21, 254-273. https://doi.org/10.1027/1016-9040/a000277 